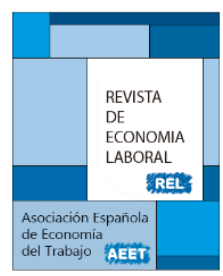

\title{
UN ANÁLISIS DINÁMICO DE LOS FLUJOS DE ENTRADA A LA FORMALIDAD EN AMÉRICA LATINA
}

\author{
Luis Beccaria ${ }^{*}$ y Roxana Maurizio** \\ * Universidad de General Sarmiento, Argentina \\ ** Instituto Interdisciplinario de Economía Política, UBA-CONICET, Argentina
}

Recibido Julio 2018; Aceptado Diciembre 2018

\section{Resumen}

Luego del incremento de la informalidad observado durante la década de los noventa, desde comienzos de la siguiente se ha verificado un proceso de formalización en una cantidad importante de paises de América Latina, si bien su magnitud difiere en cada caso. Este trabajo analiza, desde una perspectiva dinámica y comparada, la evolución de la formalidad laboral en cinco países de la región: Argentina, Brasil, Ecuador, Paraguay y Perú, durante los 2000. En particular, se evalúa la intensidad y las características de este proceso, se analizan los flujos de entrada a un trabajo formal y se identifican los principales impulsores de esta dinámica laboral positiva.

Palabras clave: informalidad, América Latina, formalización laboral.

Clasificación JEL: N36

\begin{abstract}
After the increase in informality observed during the nineties, since the beginning of the following decade a process of labour formalization has been verified in several Latin American countries, although its magnitude differs among them. This paper analyses, from a dynamic and comparative perspective, the evolution of labour formality in five Latin American countries: Argentina, Brazil, Ecuador, Paraguay and Peru, during the 2000s. In particular, it evaluates the intensity and characteristics of this process, the inflows to a formal job and the main drivers of this positive labour behaviour.
\end{abstract}

Key words: informality, Latin America, labour formalization.

JEL Classification: N36

${ }^{1}$ Correos de contacto: labeccari@gmail.com y roxanadmaurizio@gmail.com

(C) Revista de Economía Laboral 


\section{Introducción}

Desde la década de 2000, se ha observado una tendencia al aumento del empleo asalariado formal -y por ende, una reducción de la informalidad- en un conjunto importante de países en América Latina. Ello se verificó en un contexto de crecimiento económico sostenido caracterizado por una creciente demanda laboral y reducción significativa de los niveles de desempleo. ${ }^{2}$

A pesar de ello, la informalidad continúa siendo una de las características más importantes de los mercados de trabajo latinoamericanos. Bajo el término "formalidad laboral" hacemos referencia aquí al empleo asalariado cubierto por la legislación laboral y registrado en la seguridad social. ${ }^{3}$

El documento plantea que no existe un único factor que pueda explicar esta dinámica positiva observada en estos países desde comienzos de los 2000, sino que ella parece ser el resultado de varios que operan de manera combinada. En particular, el crecimiento económico sostenido hace más predecible la dinámica ocupacional y facilita que los empleadores recurran a la contratación de personal a través de contratos de trabajo de largo plazo. En este contexto, la formalización se vuelve más factible en tanto una tendencia expansiva de la demanda de mano de obra disminuye la probabilidad de despidos y, por lo tanto, de que los empleadores incurran en los costos asociados al mismo. Desde el punto de vista de los trabajadores, un contexto de crecimiento económico y mejora de las condiciones laborales, con caídas en el desempleo, eleva su capacidad de negociar las condiciones de trabajo, lo que también puede promover el registro.

Sin embargo, si bien el crecimiento económico generador de empleo aparece como una condición necesaria para el proceso de formalización, este último se potenciará cuando se ponen en marcha políticas específicas. De la misma manera, la efectividad de estas última difícilmente sea muy elevada si no actúan en contextos de aumento de la demanda de trabajo.

El objetivo de este artículo es analizar, desde una perspectiva dinámica y comparada, la evolución del empleo asalariado formal en cinco países de la región: Argentina, Brasil, Ecuador, Paraguay y Perú. En particular, se evalúa la intensidad y las características de este

\footnotetext{
${ }^{2}$ Véase, por ejemplo, Damill y Frenkel (2012); CEPAL-OIT (2015).

${ }_{3}^{3}$ Por lo tanto, los términos empleo formal o empleo asalariado registrado en las seguridad social serán utilizados intercambiablemente a lo largo del documento.
} 
proceso, se examinan en detalle los flujos de entrada a un trabajo formal y se identifican los principales impulsores de esta dinámica positiva.

El enfoque dinámico del mercado de trabajo permite un análisis de las entradas y salidas de un estado laboral específico y sirve para identificar los efectos negativos y positivos que las transiciones laborales pueden tener en el ingreso individual y del hogar, y en el bienestar. En particular, este estudio utiliza este enfoque de modo de evaluar la intensidad y características de los flujos hacia un puesto formal de manera comparada entre los cinco países aquí considerados.

El documento sigue en la sección 2 con una discusión sobre los enfoques de la formalidad y los factores potencialmente asociados a su evolución. La sección 3 presenta una descripción de las fuentes de información. La sección 4 detalla la metodología utilizada para el análisis dinámico. La sección 5 presenta una visión general de la evolución de la formalidad laboral en los países bajo estudio durante el nuevo milenio. La sección 6 analiza las estimaciones obtenidas sobre la intensidad y características de las transiciones hacia un trabajo formal. La sección 7 evalúa los factores asociados a este proceso. Finalmente, la sección 8 concluye.

\section{Marco teórico para el análisis de la formalidad laboral y su evolución en América Latina}

\subsection{Enfoques de la formalidad y de la informalidad laboral}

Como fue mencionado, el objetivo del documento es analizar la dinámica del empleo formal asalariado en los 2000s, esto es, ocupados en relación de dependencia cubiertos por las normas laborales y registrados en la seguridad social. La contraparte de estos asalariados son los trabajadores en relación de dependencia no registrados en la seguridad social, informales. Se está haciendo uso aquí del "enfoque legal" de la informalidad el que, justamente, asocia la informalidad con el incumplimiento de la normativa laboral. ${ }^{4}$

La identificación empírica de la condición de formalidad de los asalariados en cada uno de estos países se basa en la disponibilidad de información en las encuestas utilizadas. En Argentina, se considera que los asalariados formales son aquellos que responden que sus empleadores

\footnotetext{
${ }^{4}$ Para un análisis detallado de este enfoque véase ILO (2002) y Hussmanns (2004).
} 
les descuentan de sus remuneraciones los aportes para el sistema de seguridad social. En Brasil, un asalariado se clasificará como registrado si ha firmado un contrato laboral. En Paraguay y Perú, se utiliza la pregunta sobre si el empleado está o no afiliado a un sistema de pensiones. En Ecuador, aquellos que indican que reciben seguro social del trabajo se consideran asalariados registrados. A pesar de estas diferencias en la forma específica de identificar a los informales en las encuestas, la comparabilidad entre países debe considerarse razonablemente adecuada en tanto todas ellas indagan acerca del aspecto sustantivo de la idea de informalidad legal que es la falta de cobertura de las normas laborales. Debe tenerse en cuenta en este sentido, que estas distintas formas adoptadas en los relevamientos no son en todos los casos producto exclusivamente de decisiones metodológicas, sino que reflejan las normas y procedimientos existentes en cada país. Así, por ejemplo, en Argentina no se firman contratos laborales explícitamente y son precisamente formales aquellas relaciones inscriptas en el sistema de seguridad social, lo cual implica que el empleador les hace descuentos con destino al mismo. En ese caso, por tanto, no tendría sentido incluir una pregunta sobre existencia de contrato. La pregunta que se emplea en Argentina es, por tanto, prácticamente la misma a la que se recurre en Paraguay y Perú.

Vale aclarar que no todos los empleos informales corresponden a asalariados no registrados; los trabajadores independientes (cuenta propia y empleadores) también pueden clasificarse entre formales e informales. Sin embargo, en este caso los criterios a los que puede recurrirse para diferenciarlos están menos establecidos en la literatura. A veces, se toma en cuenta el cumplimiento o no de las normas impositivas y/o de seguridad social. En otros casos (la propuesta de la OIT) se identifica a los informales no asalariados a partir de su pertenencia al sector informal.

Precisamente, la noción de informalidad estuvo originariamente asociada al "enfoque productivo" a partir del cual se diferencia entre el Sector Formal (SF) y el Sector Informal (SI) y, por ende, el empleo en el SF y el empleo en el SI de la economía. En particular, el concepto de sector informal surgió a principios de los años 70, en un documento de la Organización Internacional del Trabajo (OIT, 1972). Luego, este concepto fue desarrollado en América Latina por el Programa Regional de Empleo para América Latina y el Caribe (PREALC), con el objetivo de explicar el crecimiento de amplios sectores de la población que no lograban participar en los procesos de modernización productiva. En general, el SI se asocia con los establecimientos de muy baja productividad, 
generalmente pequeños, orientados a la supervivencia más que a la acumulación capitalista. Es por ello que, bajo esta conceptualización, el SI refleja la incapacidad de las economías para generar empleo suficiente en el sector formal en comparación con el crecimiento de la fuerza de trabajo.

Siguiendo las recomendaciones de la OIT, el empleo del SI está compuesto por empleadores y asalariados en establecimientos pequeños (definidos operacionalmente, como es usual en América Latina, como aquellos con cinco ocupados o menos) y trabajadores no profesionales por cuenta propia. El sector público está excluido del SI. Por lo tanto, el empleo en el SF está constituido por asalariados y empleadores de establecimientos de más de cinco ocupados, cuentapropistas profesionales (con nivel educativo universitario) y asalariados del sector público.

Si bien a lo largo del documento el "enfoque legal” será el utilizado mayormente, especialmente en el análisis dinámico de las entradas a un puesto formal, el "enfoque productivo" también será tenido en cuenta para mostrar las vinculaciones entre ambas definiciones de formalidad. Precisamente, el tamaño y dinámica del sector informal constituye un determinante principal de la magnitud y evolución del empleo informal, no registrado. Por lo tanto, el análisis también tendrá en cuenta la característica del puesto de trabajo de esta perspectiva, esto es, si pertenece o no al sector informal.

\subsection{Factores potencialmente asociados al proceso de formalización laboral}

Teniendo en cuenta que uno de los objetivos principales de este documento es analizar los flujos de entrada a un puesto asalariado formal (desde el "enfoque legal"), registrado en la seguridad social, en los cinco países de América Latina aquí estudiados durante los 2000, en esta sección se discuten los factores que potencialmente pueden haber impulsado esta dinámica positiva. En particular, se analizan los argumentos en torno al impacto del ciclo económico, de las políticas de incentivos a la formalización y de la inspección laboral. Luego, en la sección 7 se evalúa la evidencia empírica para estos países.

\section{a) El contexto macroeconómico y la generación de empleo}

Se puede argumentar que un proceso de crecimiento sostenido con generación de empleo hace más previsible el funcionamiento del mercado 
de trabajo en el futuro, lo que tiende a favorecer la celebración de contratos de largo plazo. En este contexto, la formalización se vuelve más factible per se. Al mismo tiempo, una demanda laboral creciente también puede reducir la probabilidad esperada de despidos y, por ende, las chances de que los empresarios tengan que afrontar efectivamente los costos asociados a este proceso cuando deciden desvincular a un trabajador formal. A través de esta vía, por lo tanto, se reducen los costos (esperados) asociados a la formalidad lo que hace que los empresarios están más predispuestos a contratar trabajadores legalmente o a formalizar a aquellos que ya tenían contratado de manera informal. De esta manera, los incentivos a la informalidad asociados a los menores costos de ajuste del plantel de trabajadores frente a las diferentes fases del ciclo económico se reducen. En este contexto se ponderan los beneficios que para los propios empleadores generan las relaciones laborales largas debido al aumento de la productividad asociado a la intensificación de las tareas de entrenamiento y al mayor involucramiento de los trabajadores (Beccaria, 2015).

Por el contrario, la inestabilidad macroeconómica genera incertidumbre sobre el contexto económico y laboral futuros lo que puede incentivar la evasión de las normas laborales y, con ello, incrementar la contratación de trabajadores de manera irregular.

Adicionalmente a la menor volatilidad, el tipo de crecimiento asociado a un determinado régimen macroeconómico resulta de suma importancia para favorecer la formalización del empleo. En particular, los resultados serán diferentes si el entorno económico propicia incrementos de productividad y rentabilidad de las empresas pequeñas generando las condiciones para que éstas se formalicen y comiencen a tributar impuestos debido a las mayores posibilidades de enfrentar estos costos en el futuro. Ello, en sí mismo, es una condición necesaria para la registración de sus empleados. $\mathrm{Al}$ mismo tiempo, el crecimiento del nivel de actividad puede contribuir a una demanda laboral creciente por parte de empresas de mayor tamaño que son, en general, las que registran menores niveles de informalidad entre sus trabajadores.

Por último, desde el punto de vista de los trabajadores, el crecimiento del empleo y la reducción consecuente del desempleo les otorga una mayor capacidad de negociación frente a sus empleadores lo que puede contribuir a un mejoramiento de las condiciones laborales con impactos positivos sobre la registración.

Sin embargo, si bien el crecimiento estable con generación de empleo parece ser una condición necesaria para que el proceso de formalización del empleo se verifique, será la interacción entre éste y 
Beccaria y Maurizio / Revista de Economía Laboral 15(2) (2018), 8-56

políticas específicas lo que determinará la efectividad de las mismas y los resultados concretos en materia de registración laboral. A continuación se detallan algunos de estos instrumentos.

\section{b) Incentivos explícitos a la formalización}

Los costos laborales salariales y no salariales suelen ser otro aspecto considerado relevante en la determinación de la demanda de trabajo formal. Es por ello que algunas medidas tendientes a estimular la creación de este tipo de ocupaciones han estado focalizadas en la reducción de los costos de contratación, de las contribuciones patronales y de los costos de despido a través de regímenes especiales que abarcan al conjunto de población o a algunos grupos de empresas o trabajadores considerados más vulnerables o a las nuevas contrataciones.

Sin embargo, esta causalidad estará fuertemente mediada por otros factores tales como la fase del ciclo económico, la demanda de bienes y la importancia relativa que los gastos en personal tengan en la estructura general de costos. Tal como lo menciona Castillo et al. (2012: 224) "Para que la reducción de los costos laborales produzca efectos sobre la demanda de empleo, es necesario que exista un nivel de demanda adecuado para los bienes que se producen y que los costos laborales no se encuentren demasiado alejados de la productividad de la firma. De lo contrario, sin posibilidades de incrementar sus ventas, la reducción en las contribuciones patronales dificilmente incentivaría a las empresas a contratar nuevo personal. Además, las firmas contratarían personal solamente si el ingreso adicional que esperan obtener por la incorporación de un nuevo trabajador resultara mayor al costo laboral que se deriva de su contratación".

Adicionalmente, resulta importante tener en cuenta que la baja de aportes patronales por sí sola puede resultar insuficiente para incentivar la registración teniendo en cuenta que ésta puede conllevar incrementos de otros costos laborales, como por ejemplo, el costo salarial asociado al cumplimiento de la normativa sobre salario mínimo y negociaciones colectivas.

Al mismo tiempo, estas políticas de reducción de los costos laborales como así también los subsidios al salario pueden estar afectados por el efecto de peso muerto (cuando la contratación de personas se hubiera realizado aún en ausencia del programa) o por el efecto sustitución (cuando se despide un trabajador para contratar a otro bajo el nuevo régimen), comportamientos que reducen significativamente el efecto neto de estos programas sobre la creación neta de empleo formal. 
Como se mencionó, un aspecto importante en este sentido es la relación de estos impactos esperados con el ciclo económico. Se argumenta que en la fase expansiva es posible observar con mayor intensidad el efecto del "peso muerto" mientras que en la fase contractiva se observaría una escasa eficiencia del programa a causa del efecto de sustitución o una baja eficacia dado que las empresas no aprovecharán los incentivos si perciben que de todas maneras no necesitan aumentar su dotación de personal en el futuro (Weller, 2008).

\section{c) Inspección laboral}

Finalmente, otro de los dispositivos con los que cuenta el Estado para combatir la informalidad y hacer efectivas las normas laborales y de la seguridad social es la inspección laboral. Para ello se requiere de un sistema de fiscalización del trabajo que resulte activo, eficaz y eficiente. El fortalecimiento de la inspección laboral incrementa las probabilidades de que los empleadores tengan que afrontar los costos asociados a tener contratado personal de manera irregular. Por lo tanto, una mayor amenaza de fiscalización o mayores sanciones asociadas a la infracción a la normativa deberían ser un estímulo para la regularización de la relación laboral.

La literatura teórica sobre la economía del cumplimiento de la legislación laboral tiene entre sus estudios pioneros el de Ashenfelter y Smith (1979), quienes analizaron los incentivos que tienen las empresas para cumplir o evadir la normativa sobre salario mínimo. Si bien el estudio se focaliza en esta institución laboral, las conclusiones pueden hacerse extensivas a otras normas y regulaciones del mercado de trabajo.

Los autores parten de la idea de que el cumplimiento del salario mínimo por parte de las empresas no será voluntario sino que sólo ocurrirá si existe la inspección laboral y penalidades asociadas. Plantean la siguiente ecuación de beneficio neto esperado bajo la condición de incumplimiento de la legislación:

$$
E(\pi)=(1-\lambda) \pi(w, r, p)+\lambda \pi(M, r, p)-\lambda D
$$

donde $M$ es el salario mínimo determinado por ley, $w$ es el salario que pagaría el empleador en ausencia de la legislación, $r$ el costo de otros factores de la producción, $p$ el precio de venta del producto, $\lambda$ la probabilidad de ser fiscalizado y descubierto en infracción y $D$ la penalidad recibida en ese caso. La ecuación indica que el beneficio esperado surge a partir de la ponderación de las dos situaciones, ser o no 
fiscalizado, donde luego se resta la penalidad en caso de ser encontrado en infracción.

A partir de allí, el empleador decidirá no cumplir con la legislación si el beneficio esperado de tal decisión $(E(\pi))$ es superior al beneficio conocido de cumplir con la misma $(\pi(M, r, p))$ :

$$
E(\pi)-\pi(M, r, p)=(1-\lambda)[\pi(w, r, p)-\pi(M, r, p)]-\lambda D>0[2]
$$

La ecuación indica que la decisión de no cumplir se correlaciona positivamente con la brecha entre el salario estipulado por la ley y el que se le pagaría al trabajador, y negativamente con la probabilidad de ser encontrado en infracción (lo cual depende de la probabilidad de recibir una inspección y de que los inspectores efectivamente descubran situaciones irregulares) y del valor esperado de la penalidad. Asimismo, ciertos atributos del establecimiento productivo y de los trabajadores también pueden correlacionarse positivamente con el no cumplimiento. Entre ellos, las menores calificaciones que hacen más probable que el salario de mercado sea inferior al salario mínimo o las características de las firmas o del sector que dificultan las tareas de inspección (como el tamaño del establecimiento, la intensidad de rotación de las firmas o el ocultamiento de los lugares de trabajo).

\section{Fuentes de información}

Los datos usados en este documento provienen de las encuestas de hogares realizadas por los institutos nacionales de estadística de cada país. En algunos de ellos se utilizan dos relevamientos diferentes, uno para el análisis estático de la sección 5 y otro para el análisis dinámico de la sección 6 , tal como se detalla a continuación. El período bajo análisis comienza en 2003/2004, en la mayoría de los casos, y se extiende hasta 2015/2017, dependiendo de la disponibilidad de información.

La selección de los países estuvo determinada por dos factores. El primero, la disponibilidad de datos de panel que permitan llevar a cabo el análisis de los flujos de entrada a un puesto formal; el segundo, la posibilidad de incorporar al estudio países con mercados de trabajo muy diferentes entre sí lo que permite obtener una mirada exhaustiva sobre la dinámica laboral en América Latina.

Para Argentina, la única fuente de datos usada es la Encuesta Permanente de Hogares (EPH), la cual sólo cubre áreas urbanas del país. El período considerado es 2003-2017. 
La Encuesta Nacional de Empleo, Desempleo y Subempleo (ENEMDU) en Ecuador se lleva a cabo en áreas urbanas y rurales, por lo que tiene cobertura nacional. El período es el mismo que para Argentina. La Encuesta Nacional de Hogares (ENAHO) en Perú también tiene representatividad nacional. El período bajo análisis es 2002-2015. En cada uno de los dos países restantes se usaron dos encuestas. En Brasil, se utilizó, por un lado, la Pesquisa Mensal de Emprego (PME) que cubre las seis principales áreas urbanas y, por otro, la Pesquisa Nacional por Amostra de Domicílios (PNAD), con cobertura nacional. En el primer caso el período considerado fue 2003-2017, mientras que en el segundo fue 2003-2015. Finalmente, en Paraguay se usaron la Encuesta Permanente de Empleo (EPH), con cobertura nacional, para los años comprendidos entre 2004-2017, y la Encuesta Continua de Empleo (ECE), que cubre sólo Gran Asunción, para el período 2010-2015.

Aunque las encuestas de los países en estudio no son longitudinales, las muestras de paneles rotativos que utilizan algunas de ellas permiten construir datos de panel. En dichos esquemas, la muestra total se divide en un cierto número de grupos de hogares y cada grupo permanece en ella durante una cantidad determinada de períodos de observación. Este esquema de rotación caracteriza a la EPH de Argentina, la PME de Brasil, la ENEMDU de Ecuador, la ECE de Paraguay y la ENAHO de Perú.

Para obtener bases de datos de panel comparables entre países, se consideró una transición para cada individuo, la que surge de comparar los estados de dos observaciones sucesivas entre las que media un año. Este documento utiliza datos sobre la situación ocupacional en el mes t + 12 de personas que estuvieron empleadas en el mes t. Específicamente, se analizan las características individuales y de la ocupación iniciales de aquellos individuos que no eran asalariados formales en el momento inicial y que transitaron hacia la formalidad durante los 12 meses siguientes.

Además de usar la estructura del panel de la muestra, este documento también emplea información retrospectiva. Específicamente, a todos los trabajadores se les pregunta cuánto tiempo han estado en sus trabajos actuales, lo cual permite definir la variable "antigüedad en el puesto", que se utilizó para identificar si una persona que estaba ocupada tanto en el mes t como en el mes $t+12$, lo había estado en el mismo empleo o había cambiado a otro. Si respondieron en la segunda observación que habían estado en su trabajo actual durante más de un año, se entendió que no habían cambiado de trabajo entre las dos observaciones. Estas encuestas no investigan las causas de la separación 
del trabajo, por lo que no se puede distinguir entre el despido y la separación voluntaria.

El estudio está restringido a trabajadores hombres ocupados entre 15 y 65 años y a mujeres ocupadas entre 15 y 60 años. Debido a que no todas las encuestas utilizadas son representativas del conjunto de la población del país, y dado que los mercados laborales en las zonas rurales y los centros urbanos pueden comportarse de manera diferente, el análisis se restringió a las áreas urbanas.

Finalmente, de modo de contar con suficiente cantidad de observaciones se construyó para cada país un pool de los paneles anuales por lo que los resultados reflejarán el promedio de los años considerados en cada caso. La cantidad de observaciones muestrales incluidas en el pool de paneles es el siguiente: 191.352 en Argentina, 1.054.215 en Brasil, 66.898 en Ecuador, 3.714 en Paraguay y 6.121 en Perú.

\section{Metodología para el análisis dinámico}

Como fue mencionado, uno de los objetivos principales de este documento es analizar los flujos de entrada a un puesto asalariado formal, registrado en la seguridad social. Para ello se estudiarán, en primer lugar, los dos canales a través de los cuales este proceso tuvo lugar en los países considerados; por otro, se analizan las características de los individuos involucrados en cada uno de esos dos procesos.

En relación a lo primero, desde una perspectiva dinámica, la formalización puede tener lugar a través de dos canales: (1) formalización in situ, es decir, un trabajador se vuelve formal en la misma ocupación entre el mes t y el mes $\mathrm{t}+12$; y (2) transición hacia un puesto de trabajo asalariado formal proveniente de un estado laboral diferente (asalariado informal o independiente, desempleo o inactividad).

A su vez, para analizar la contribución de los diferentes grupos de trabajadores a la formalización a través del segundo canal, es posible comenzar con la siguiente ecuación:

$$
\frac{f_{i j}}{F_{j}}=\frac{S_{i} \times P\left(E_{i j}\right)}{F_{j}}
$$

donde $f_{i j}$ indica la transición del estado i (cualquier estado laboral que no sea un trabajo formal) en $t$ al estado $j$ (trabajo formal) en $t+12$; $F_{j}$ indica las transiciones totales desde cualquier estado en $t$ hasta el estado j (trabajo formal) en $\mathrm{t}+12 ; S_{i}$ indica el stock de individuos no 
formales (trabajadores informales o independientes, desempleados o inactivos) en t; $P\left(E_{i j}\right)$ indica el porcentaje de transición del estado i en $\mathrm{t}$ al estado j (trabajo formal) en $\mathrm{t}+12$; e $i \neq j$.

A su vez, la frecuencia con la que se ingresa a la formalidad $P\left(E_{i j}\right)$ puede descomponerse en dos factores: por un lado, la intensidad con la que se abandona el estado inicial (diferente de un trabajo formal) $-P\left(E_{i}\right)-$, y por otro lado, la intensidad con la que se ingresa a un trabajo formal después de dejar el estado inicial $-P\left(E_{j} \mid E_{i}\right)-$ :

$$
P\left(E_{i j}\right)=P\left(E_{j} \mid E_{i}\right) P\left(E_{i}\right)
$$

Bajo la consideración de convergencia estocástica, las frecuencias relativas obtenidas aquí pueden ser interpretadas como probabilidades.

Esta descomposición permite evaluar hasta qué punto las transiciones a la formalidad de determinados grupos de personas están asociadas a su participación relativa inicial en el empleo no formal y a la frecuencia de tránsitos hacia la formalidad. También es posible evaluar en qué medida esta última depende, a su vez, de la frecuencia (probabilidad) con la que estos individuos abandonan el estado inicial y de las posibilidades de pasar a la formalidad una vez que dejan su estado inicial (probabilidad condicional). ${ }^{5}$

\section{A modo de contexto: evolución de la formalidad laboral en América Latina durante el nuevo milenio 6}

Hacia el 2014, OIT estimaba que los asalariados registrados (formales) constituían el 76\% del total de asalariados (80\% si se excluye a los asalariados del servicio doméstico). ${ }^{7}$ Estas proporciones eran del $86 \%$ entre los que se desempeñaban en establecimiento del sector formal

\footnotetext{
5 Esta descomposición fue utilizada por Jenkins y Schluter (2003) y por Cantó et al. (2005), para el análisis dinámico de la pobreza en países europeos. Maurizio (2015) usó esta misma metodología para el estudio del proceso de formalización en Argentina y Brasil durante el nuevo milenio.

${ }^{6}$ Entre los estudios previos sobre la formalidad laboral en diferentes países de América Latina se encuentran Amarante y Arim (2015); Bertranou et al. (2013); Beccaria et al. (2015a, 2015b); Berg (2010); Corseuil y Foguel (2012); FORLAC (2014a); Maurizio (2015); Maurizio y Vázquez (2015).

7 El último dato con el cual se cuenta para la región en su conjunto proveniente de OIT es 2014 .
} 
(establecimientos de más de 5 ocupados) y del $44 \%$ de los que lo hacían en el sector informal; esta última era similar en el servicio doméstico (40\%). Con relación al total de ocupados, los asalariados registrados representaban algo más de la mitad (55\%), en promedio para la región.

Desde la perspectiva de la distribución de los asalariados no registrados (informales), estas diferencias de incidencia se traducen en que el $63 \%$ de ellos se concentre en unidades pequeñas, y en el servicio doméstico; sin embargo, también se deduce que no es despreciable la proporción que trabaja en unidades del sector formal (cuadro 1). O sea, si bien en promedio, alrededor de dos tercios de los asalariados no registrados desarrollan sus tareas en establecimientos pequeños, el tercio restante lo hace en firmas medianas y grandes.

Cuadro 1. Incidencia de la formalidad laboral en América Latina. Fuente: estimaciones propias sobre la base de datos de la OIT y de las encuestas de hogares de los países bajo estudio.

\begin{tabular}{|c|c|c|c|c|c|c|}
\hline & \multirow{2}{*}{$\begin{array}{c}\text { América Latina } \\
\text { (información OIT) 1/ }\end{array}$} & \multicolumn{5}{|c|}{ Información de las encuesta nacionales $2 /$} \\
\hline & & Argentina & Brasil & Ecuador & Paraguay & Perú \\
\hline \multirow{2}{*}{\multicolumn{7}{|c|}{$\begin{array}{l}\text { Incidencia de los asalariados } \\
\text { registrados }\end{array}$}} \\
\hline & & & & & & \\
\hline Asalariados & 76 & 67 & 83 & 70 & 42 & 60 \\
\hline Sector Formal & 88 & 83 & 91 & 87 & 58 & 75 \\
\hline Sector Informal & 43 & 29 & 42 & 26 & 13 & 22 \\
\hline \multicolumn{7}{|l|}{ Proporción de asalariados no } \\
\hline registrados en el SI & 63 & 63 & 54 & 70 & 56 & 58 \\
\hline \multicolumn{7}{|l|}{ Proporción de asalariados } \\
\hline registrados en el total de ocupados & 55 & 50 & 64 & 47 & 29 & 36 \\
\hline $\begin{array}{l}\text { Proporción de No Asalariados en el } \\
\text { total de ocupados }\end{array}$ & 28 & 24 & 23 & 33 & 33 & 40 \\
\hline
\end{tabular}

Cuando se analizan específicamente los cinco países incluidos en este documento se observa que la incidencia de la formalidad en el conjunto de los asalariados es más elevada en Brasil (83\%) que en el resto de los países. Entre éstos se observan amplias diferencias, ya que la formalidad varía entre el 67\% en Argentina y el 42\% en Paraguay (cuadro 1). Precisamente en este último país, y en Perú, menos del $40 \%$ del empleo total corresponde a asalariados registrados, aunque en el primero de esos países ello obedece más a esa baja formalización entre todos los asalariados mientras que en Perú resulta significativa la presencia de puestos no asalariados en el total del empleo urbano. Nuevamente Brasil 
es el país donde los asalariados registrados representan la mayor proporción de la ocupación agregada (64\%), seguido por Argentina y Ecuador con alrededor del 50\%, mientras que en los restantes dos países estos valores oscilan entre el $30 \%$ y el $36 \%$.

En los cinco casos, si bien la mayor parte de los puestos no registrados se concentran en el SI, con un máximo de $70 \%$ en Ecuador, y valores entre $54 \%$ y $63 \%$ en el resto, al igual que para el conjunto de América Latina, la cantidad de ocupaciones informales también es relevante entre las unidades productivas de tamaño mediano y grande.

Estos altos niveles de informalidad que se observan actualmente tanto para el conjunto de la región, como para los países analizados, constituyen rasgos estructurales de las economías de América Latina. Sin embargo, y tal como se manifestó en la Introducción, la región experimentó durante buena parte del período iniciado a principios de los años 2000 un significativo proceso de crecimiento económico y mejora de las condiciones del mercado de trabajo. Ello se tradujo, por ejemplo, en aumentos significativos en la tasa de empleo y descensos en la tasa de desocupación regionales (gráfico 1).

En este contexto se advierte un paulatino aumento de la participación del empleo asalariado formal desde principios de la década (cuadro 2). Las cifras de la OIT para el conjunto de la región, sólo disponibles hasta 2014, exhiben un aumento de casi 15 puntos porcentuales, tanto cuando se lo compara con el conjunto de los asalariados como con el total de ocupados. En los cinco países analizados en este documento, la intensidad del aumento fue -considerando el promedio simple de las tasas- algo mayor entre el 2005 y el 2014, pero levemente menor si se toma en cuenta el ponderado por la cantidad de ocupados de cada país (que es la forma de computar el dato por parte de la OIT para el promedio regional) debido a la expansión menos intensa que registró Brasil, país que partía de niveles mayores de formalidad. Extrapolando al resto de la región la dinámica que muestra la estructura del empleo en estos países con posterioridad a 2014, se concluiría que aquella disminución de 15 puntos porcentuales registrada hasta ese año en la proporción de asalariados registrados también reflejaría el cambio acontecido entre los años 2000 y 2017.

El incremento en la proporción de ocupaciones formales en un marco de aumento del empleo total significó que la creación de puestos de trabajo registrados en la seguridad social fuera muy importante en varios países. Para el conjunto de la región lo hizo a un ritmo anual del $3.9 \%$ entre 2005 y 2014. Entre los países considerados llegó a casi el 9\% por año en Perú y al 7,6\% en Ecuador y Paraguay entre esos mismos años, 
o al $6.6 \%, 7.4 \%$ y $6.3 \%$, respectivamente, cuando se considera el período 2005-2017.

Gráfico 1. Evolución del PIB, el empleo y la desocupación en América Latina. Fuente: elaboración propia con la base de datos de la CEPAL y la OIT.

PIB (tasa anual de crecimiento)

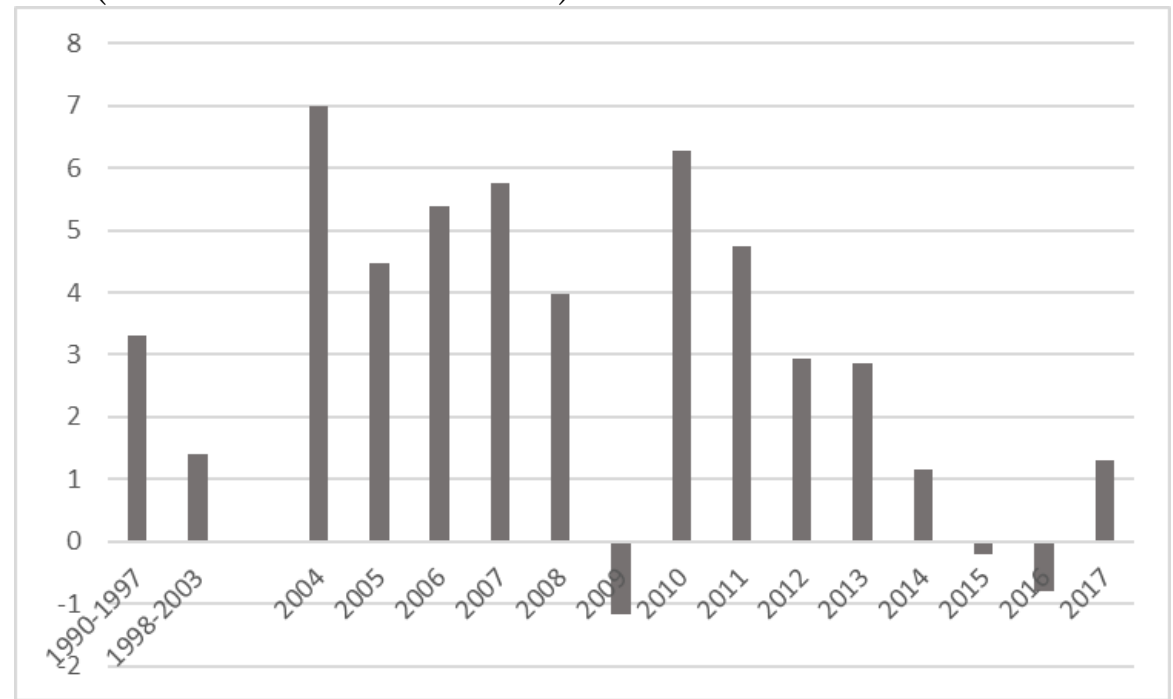

Empleo y desocupación

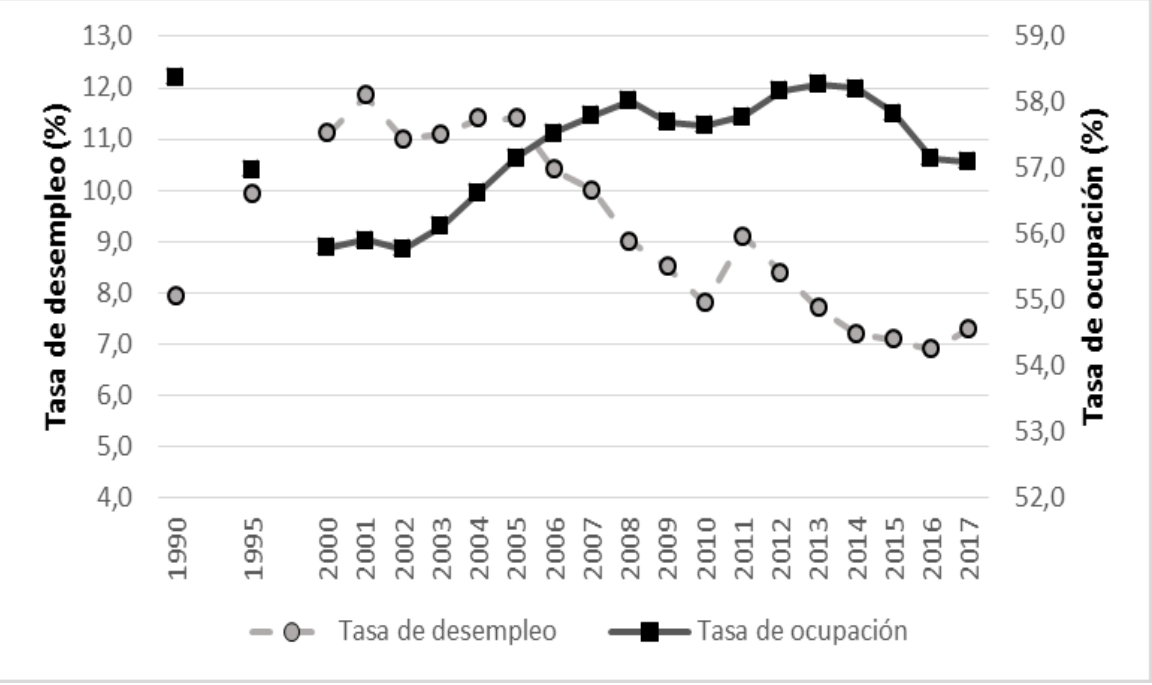


Cuadro 2. Evolución de la proporción de asalariados registrados en el empleo. Fuente: estimaciones propias sobre la base de datos de la OIT y de las encuestas de hogares de los países bajo estudio.

\begin{tabular}{|c|c|c|c|c|c|c|}
\hline & $\begin{array}{c}\text { América } \\
\text { Latina }\end{array}$ & Argentina & Brasil & Ecuador & Paraguay & Perú \\
\hline \multicolumn{7}{|c|}{ Como proporción del total de asalariados } \\
\hline 1990 & 64 & & & & & \\
\hline 1995 & 61 & & & & & \\
\hline 2000 & 60 & & & & & \\
\hline 2005 & 63 & 55 & 71 & 43 & 31 & 41 \\
\hline 2010 & 72 & 65 & 77 & 53 & 37 & 54 \\
\hline 2014 & 76 & 67 & 83 & 65 & 40 & 61 \\
\hline 2015 & & 67 & 83 & 66 & 43 & 59 \\
\hline 2016 & & 67 & & 64 & 42 & 60 \\
\hline 2017 & & 67 & & 70 & 42 & 60 \\
\hline \multicolumn{7}{|c|}{ Como proporción del total de ocupados } \\
\hline 1990 & 45 & & & & & \\
\hline 1995 & 42 & & & & & \\
\hline 2000 & 41 & & & & & \\
\hline 2005 & 43 & 42 & 53 & 26 & 20 & 23 \\
\hline 2010 & 51 & 51 & 60 & 33 & 25 & 31 \\
\hline 2014 & 55 & 52 & 65 & 42 & 28 & 37 \\
\hline 2015 & & 52 & 64 & 41 & 30 & 37 \\
\hline 2016 & & 51 & & 38 & 29 & 37 \\
\hline 2017 & & 50 & & 47 & 29 & 36 \\
\hline
\end{tabular}

Esta evolución del nivel de actividad agregado y del mercado trabajo significó un cambio de la tendencia que caracterizó a los años noventa. En este decenio, el crecimiento agregado, si bien no fue reducido, especialmente en los primeros años, tuvo escaso impacto sobre la creación de puestos de trabajo. Ello se observa en la disminución de la tasa de ocupación y en el aumento del desempleo. Simultáneamente, creció la informalidad, proceso que se verificó con mayor intensidad durante la primera parte de la década, precisamente cuando la economía, como se señaló, creció a mayor ritmo.

Respecto a la evolución económica y laboral iniciada a principios del nuevo siglo, se advierte que la expansión productiva fue intensa hasta 2011 (con excepción de 2009), luego se moderó y ya en 2015 y 2016 el PIB 
se contrajo. La dinámica laboral no fue ajena a esos vaivenes; así, la creación de empleo fue afectada por la recesión de 2009 pero se recuperó posteriormente respondiendo a lo acontecido con la producción agregada. Sin embargo, se observa que la tasa de empleo se estancó en 2012 y comenzó a caer desde 2014. La desocupación, por su parte, continuó reduciéndose (salvo durante el episodio de la crisis internacional) hasta 2014.

En el marco de esta desaceleración, y luego reversión, de la mejora que venía registrando el mercado de trabajo desde 2012, la proporción de asalariados registrados continuó reduciéndose inicialmente. Para el conjunto de América Latina, ello se observa al menos hasta 2014 (último año para el cual se dispone de información del agregado regional), lo cual sugiere que la disminución del crecimiento y la menor creación de empleo que se verificó hacia el 2009 no habría tenido un impacto sobre el comportamiento de esa variable.

Con posterioridad a 2014, sin embargo, las estimaciones realizadas para los cinco países dan cuenta que el proceso de formalización se detuvo, con la única excepción del aumento registrado en Ecuador en 2017 luego de haber también mostrado una estabilidad en los dos años anteriores. Sobre este aspecto se volverá en la sección 7.1, pero vale señalar aquí que el gráfico 2, que allí se incluye, permite visualizar cómo el estancamiento de la proporción de trabajadores no registrados que se observa en cada país hacia el final del período está ligado a la dinámica económica más general que ellos exhiben. Así, el mantenimiento de los niveles de formalización en Paraguay y Perú que se verifica desde 2014/15 se asocia a la desaceleración del PIB y al crecimiento de la desocupación. En Argentina, este proceso parece iniciarse anteriormente, hacia el 2012, cuando empieza a atravesar una etapa de marcados vaivenes en su crecimiento; la tasa de desempleo ya se había estabilizado incluso uno años antes. El hecho que la información para Brasil sólo se encuentre disponible hasta 2015 impide realiza un análisis similar, pero también se verifica en este caso que el peso de los informales dejó de caer en 2015, cuando el PIB cayó de manera marcada y el desempleo se elevó.

Por lo tanto, más allá de esta desaceleración en el crecimiento de la proporción de asalariados formales en el empleo urbano de los últimos años, durante los 2000 la formalidad laboral ha experimentado una tendencia alcista que contrasta claramente con la observada durante la década de los noventa en la región. De allí la importancia de analizar la intensidad y características de los flujos de entrada a un puesto formal 
desde una perspectiva dinámica. Sobre estos aspectos se avanza en la sección siguiente.

\section{El proceso de formalización desde una perspectiva dinámica}

Dado que el período bajo estudio se caracteriza por un aumento absoluto y relativo de los puestos formales, el siguiente análisis se centrará exclusivamente en los cambios brutos experimentados por la cantidad de empleos asalariados formales. En la sección 6.1 se evalúa la intensidad de las entradas a la formalidad a través de los canales explicitados anteriormente, en la sección 6.2 se estudian las características del proceso de formalización en el mismo puesto y, finalmente, en la sección 6.3 se realiza un análisis similar para las entradas desde otra ocupación, el desempleo o la inactividad.

\subsection{Intensidad y canales de entrada a un puesto formal}

Tal como se detalló en la sección metodológica, el proceso de formalización se desagregará según los dos tipos de mecanismos que lo explican: la formalización in situ (esto es, la regularización de un puesto que era inicialmente informal) y las entradas a una ocupación formal a través de transiciones desde otro estado laboral. A su vez, aquí se diferencian las entradas desde otra ocupación y las entradas desde el desempleo o la inactividad.

Como se muestra en el cuadro 3 , en todos los casos excepto en Perú, la mayor parte del aumento bruto de puestos formales se verificó en la misma ocupación. Esto es, una porción significativa de los asalariados que se convirtieron en formales lo hicieron sin cambiar de puesto de trabajo: alrededor del 30\% en Brasil y Perú, y del $40 \%$ en Argentina, Ecuador y Paraguay. Estas elevadas proporciones de formalización in situ resultan sorprendentes, aunque podrían haber obedecido al papel de ciertas políticas públicas -que se analizan en detalle en la sección 7-destinadas a generar las condiciones apropiadas para que este proceso tenga lugar.

Adicionalmente, entre el 26\% (Brasil), y el 44\% (Perú) de los nuevos puestos formales fueron ocupados por personas que, un año antes, trabajaban en otra ocupación de carácter no formal (asalariados no registrados o independientes). Este es el principal canal de formalización 
Beccaria y Maurizio / Revista de Economía Laboral 15(2) (2018), 8-56

laboral sólo en este último país. Finalmente, los tránsitos desde el desempleo o la inactividad explican alrededor del 30/40\% de los flujos de entradas a un puesto formal. Dicho porcentaje es de $26 \%$ en el caso de Paraguay.

Cuadro 3. Canales de entrada a la formalidad. Fuente: estimaciones propias sobre la base de las encuestas de hogares de los países bajo estudio.

\begin{tabular}{|c|c|c|c|c|c|}
\hline & Argentina & Brasil & Ecuador & Paraguay & Perú \\
\hline Formalización en el mismo puesto & 41.3 & 30.3 & 38.7 & 41.0 & 28.0 \\
\hline Asalariados no registrados & 32.7 & 23.6 & 31.1 & 38.5 & 23.4 \\
\hline No asalariados & 8.6 & 6.6 & 7.6 & 2.4 & 4.6 \\
\hline Formalización cambiando de puesto & 26.3 & 26.0 & 32.4 & 33.4 & 43.7 \\
\hline Asalariados no registrados & 18.9 & 18.8 & 23.1 & 27.2 & 24.9 \\
\hline No asalariados & 7.5 & 7.2 & 9.3 & 6.2 & 18.9 \\
\hline Desocupados & 15.9 & 19.4 & 11.4 & 11.9 & 13.9 \\
\hline Inactivos & 16.5 & 24.4 & 17.5 & 13.8 & 14.4 \\
\hline TOTAL & 100 & 100 & 100 & 100 & 100 \\
\hline
\end{tabular}

Asimismo, cuando se analizan con mayor detalle estas transiciones, se observa que la formalización in situ de aquellos que eran inicialmente asalariados no registrados da cuenta de la mayoría de las entradas a la formalidad. Perú es la única excepción. Más adelante se estudiarán los factores asociados a tal proceso.

Previo a ello, en lo que sigue se analizará, en primer lugar, los atributos personales y las características de los trabajos de aquellos ocupados que se formalizaron a través del primer canal; en segundo lugar, se examinarán las características de aquellos que ingresaron a una ocupación formal proviniendo de otra ocupación no formal, el desempleo o la inactividad.

\subsection{Las caracteristicas del proceso de formalización en el mismo puesto}

El cuadro 4 presenta para diferentes grupos de trabajadores: (1) la tasa de formalidad en el año inicial de cada país (porcentaje inicial de asalariados formales en el empleo total), (2) porcentaje de trabajadores no formales en $t$ que se formalizaron en $t+12$, y (3) la contribución de cada grupo de trabajadores al proceso de formalización en la misma ocupación. 

Cuadro 4. Formalización en el mismo puesto. Fuente: estimaciones propias sobre la base de las encuestas de hogares de los países bajo estudio.

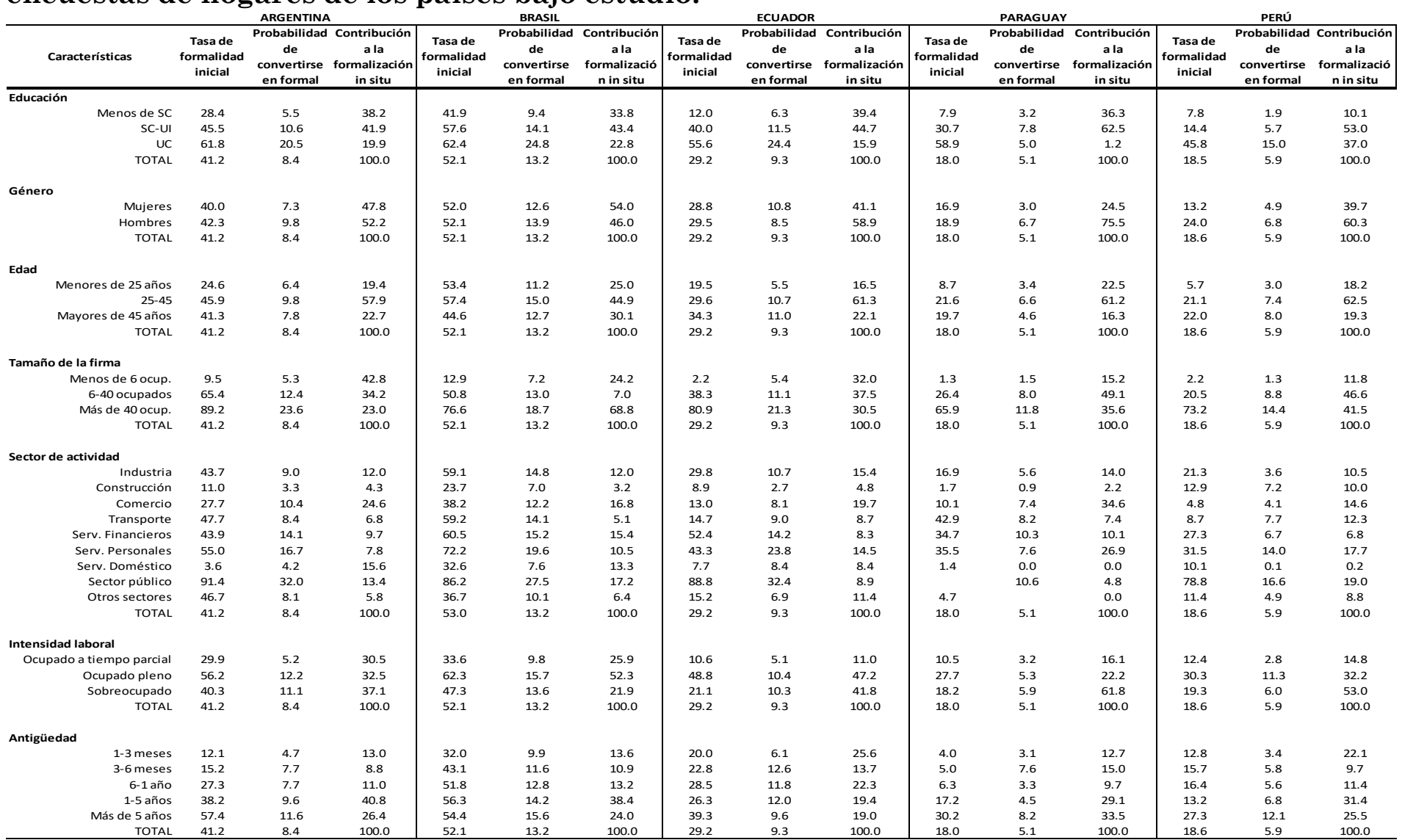

C Revista de Economía Laboral 

El cuadro muestra dos resultados importantes para todos los países considerados. En primer lugar, la formalización a través de este canal se verificó para todas las categorías de trabajadores. Segundo, aquellos grupos que presentaban una tasa de registración relativamente más alta al comienzo del período se beneficiaron más intensamente de este proceso que el resto de los trabajadores.

En particular, tanto la tasa de empleo formal inicial como la frecuencia con la que pasan a ese estado aumentan con el nivel educativo en todos los países. Sin embargo, dado que los trabajadores con escolarización intermedia - secundaria completa y terciaria incompletaconstituyeron el mayor grupo de trabajadores no formales, fueron los que hicieron la mayor contribución a este proceso.

Con respecto al género, los hombres -que presentaban las tasas de formalidad más altas al inicio del período- se han beneficiado más de este proceso que las mujeres (excepto en Ecuador). Sin embargo, la diferencia en la intensidad de la formalización entre hombres y mujeres no fue muy importante.

Se encontró una forma de U invertida para la relación entre la formalización y la edad en Argentina, Brasil y Paraguay: las personas de mediana edad experimentaron la mayor probabilidad de formalizarse en el mismo trabajo. En Ecuador y Perú, en cambio, se verificó una correlación positiva entre ambas variables. En todos los casos, por lo tanto, los jóvenes tuvieron menos probabilidades de alcanzar un puesto de asalariado registrado por lo que las brechas de formalidad entre los grupos de edad se ampliaron. De todos modos, las personas de mediana edad representaron en todos los países más de la mitad de las transiciones totales a la formalidad.

Es también generalizada la asociación directa entre la frecuencia de formalización y el tamaño de la empresa; por tanto, nuevamente, este proceso implicó un incremento en la brecha de formalidad entre las empresas grandes y pequeñas a lo largo del período.

Los trabajadores a tiempo completo exhibieron las mayores chances de pasar a un puesto de asalariado registrado (excepto en Paraguay), seguidos por los sobre - ocupados y luego por los de jornada parcial. De nuevo, esta situación tendió a profundizar las brechas en la tasa de formalidad observadas al comienzo del período entre estos grupos de trabajadores.

Con respecto al sector de actividad, tanto las tasas de formalidad iniciales como las frecuencias de formalización muestran los mismos resultados en todos los países. En particular, los trabajadores del sector público enfrentan las mayores intensidades de formalización, mientras

(C) Revista de Economía Laboral 
que los trabajadores en la construcción y los servicios domésticos se enfrentan, en general, a las más bajas. En el caso particular del servicio doméstico, se puede observar que a pesar de la aplicación de medidas específicas que apuntaron a promover la formalización de los trabajadores, ${ }^{8}$ este sector continúa exhibiendo una de las tasas de informalidad más elevadas.

Finalmente, la formalización in situ ha mostrado una relación positiva con la antigüedad en el puesto (excepto en Ecuador). Esto significa que los empleadores han preferido regularizar a los empleados que han trabajado en la firma durante un período de tiempo más prolongado. De nuevo, la brecha de formalidad inicial aumentó durante el período considerado.

De modo de evaluar si estos resultados se mantienen cuando se analizan cada una de estas dimensiones de manera separada, controlando por el resto de los atributos aquí estudiados, se llevaron a cabo regresiones probit donde la variable dependiente toma el valor 1 si el trabajador es formalizado en el mismo puesto y el valor 0 si el trabajador continúa siendo informal. Los resultados son presentados en el cuadro 5.

En todos los países, excepto en Paraguay, se observa una correlación positiva entre la probabilidad de ser formalizado y el nivel educativo. Al igual que los resultados descriptivos, salvo en Ecuador, en el resto de los países el proceso de formalización in situ fue más intenso entre los hombres que entre las mujeres.

En relación a la edad, los jóvenes en Brasil y Perú experimentaron menores probabilidades de ser registrados que el resto de los ocupados. En el resto de los países, si bien los coeficientes correspondientes a los dos grupos etarios siguientes presentan signos positivos, los mismos no resultaron ser estadísticamente significativos.

Consistente con los resultados descriptivos, en todos los países el tamaño de la empresa ha contribuido positiva y significativamente al proceso de formalización en la misma ocupación. Asimismo, excepto en Paraguay, la intensidad horaria también resultó ser una dimensión explicativa de las diferentes tasas de registración donde los trabajadores a tiempo completo fueron beneficiados por este proceso con mayor intensidad que aquellos trabajando de manera part-time.

${ }^{8}$ FORLAC (2016), Bertranou et al. (2013), Madalozzo y Bortoluzzo (2011). 
Cuadro 5. Regresiones probit. Probabilidad de ser formalizado en el mismo puesto.

\begin{tabular}{|c|c|c|c|c|c|}
\hline Covariables & ARGENTINA & BRASIL & ECUADOR & PARAGUAY & PERU \\
\hline \multirow[t]{2}{*}{ SC-TI } & $0.169^{\star \star \star}$ & $0.111^{* * *}$ & $0.382^{* \star *}$ & 0.335 & $0.679^{* * *}$ \\
\hline & {$[0.0327]$} & [0.0143] & {$[0.0481]$} & [0.211] & [0.254] \\
\hline \multirow[t]{2}{*}{ TC } & $0.120^{\star *}$ & $0.170^{\star * *}$ & $0.500^{* * *}$ & -0.179 & $1.133^{\star \star *}$ \\
\hline & {$[0.0553]$} & {$[0.0207]$} & {$[0.0828]$} & [0.598] & [0.305] \\
\hline \multirow[t]{2}{*}{ Sexo } & $0.0869^{* *}$ & $0.0475^{\star \star *}$ & -0.0406 & $0.269^{* *}$ & $0.295^{\star \star}$ \\
\hline & {$[0.0391]$} & [0.0142] & {$[0.0527]$} & {$[0.213]$} & {$[0.221]$} \\
\hline \multirow[t]{2}{*}{$25-45$} & 0.0446 & $0.0459 * * *$ & 0.0665 & 0.374 & $0.238^{\star *}$ \\
\hline & {$[0.0407]$} & [0.0167] & {$[0.0601]$} & {$[0.230]$} & {$[0.239]$} \\
\hline \multirow[t]{2}{*}{ Más de 45} & 0.0437 & $0.135^{\star * *}$ & 0.0861 & 0.417 & $0.600^{\star *}$ \\
\hline & {$[0.0480]$} & {$[0.0184]$} & {$[0.0734]$} & [0.315] & [0.298] \\
\hline \multirow[t]{2}{*}{ 6-40 ocupados } & $0.468^{* \star *}$ & $0.377^{* * *}$ & $0.591^{* * *}$ & $0.595^{\star \star \star}$ & $0.870^{* * *}$ \\
\hline & {$[0.0368]$} & {$[0.0259]$} & {$[0.0519]$} & {$[0.228]$} & {$[0.237]$} \\
\hline \multirow[t]{2}{*}{ Más de 40 ocup. } & $0.648^{* * *}$ & $0.597^{* * *}$ & $1.099^{* * *}$ & $0.775^{\star \star \star}$ & $1.126^{\star \star *}$ \\
\hline & {$[0.0527]$} & {$[0.0178]$} & {$[0.0701]$} & [0.272] & [0.287] \\
\hline \multirow[t]{2}{*}{ Industria } & $-0.565^{\star * *}$ & $-0.434^{\star \star \star}$ & $-0.260^{\star \star}$ & 0.0995 & -0.0728 \\
\hline & {$[0.0742]$} & {$[0.0264]$} & [0.127] & {$[0.495]$} & [0.382] \\
\hline \multirow[t]{2}{*}{ Construcción } & $-0.768^{\star * \star}$ & $-0.749^{\star \star \star}$ & $-0.914^{* * *}$ & -0.891 & 0.705 \\
\hline & {$[0.0794]$} & {$[0.0354]$} & {$[0.139]$} & {$[0.640]$} & {$[0.483]$} \\
\hline \multirow[t]{2}{*}{ Comercio } & $-0.288^{* * *}$ & $-0.447^{\star * *}$ & $-0.258^{\star \star}$ & 0.120 & 0.216 \\
\hline & {$[0.0677]$} & {$[0.0250]$} & {$[0.125]$} & {$[0.478]$} & {$[0.380]$} \\
\hline \multirow[t]{2}{*}{ Transporte } & $-0.724^{\star \star \star}$ & $-0.505^{\star \star \star}$ & $-0.314^{\star \star}$ & 0.152 & 0.0460 \\
\hline & {$[0.0796]$} & {$[0.0335]$} & {$[0.137]$} & {$[0.560]$} & {$[0.396]$} \\
\hline \multirow[t]{2}{*}{ Serv. Financieros } & $-0.282^{* * *}$ & $-0.473^{\star * *}$ & $0.255^{\star}$ & 0.121 & 0.309 \\
\hline & {$[0.0780]$} & {$[0.0239]$} & {$[0.150]$} & {$[0.546]$} & [0.453] \\
\hline \multirow[t]{2}{*}{ Serv. Personales } & $-0.288^{\star * *}$ & $-0.274^{\star \star \star}$ & 0.143 & -0.146 & 0.280 \\
\hline & {$[0.0786]$} & {$[0.0267]$} & [0.135] & [0.499] & [0.447] \\
\hline \multirow[t]{2}{*}{ Serv. Doméstico } & $-0.599^{\star \star *}$ & $-0.446^{\star \star \star}$ & 0.222 & & \\
\hline & {$[0.0733]$} & [0.0292] & {$[0.148]$} & & \\
\hline \multirow[t]{2}{*}{ Otros sectores } & $-0.367^{\star * *}$ & $-0.770^{\star * \star}$ & $-0.535^{\star * *}$ & & -0.342 \\
\hline & {$[0.0790]$} & {$[0.0282]$} & {$[0.125]$} & & {$[0.443]$} \\
\hline \multirow[t]{2}{*}{ Ocupado pleno } & $0.246^{\star \star \star}$ & $0.287^{\star \star \star}$ & $0.355^{\star \star \star}$ & 0.0663 & $0.521^{*}$ \\
\hline & {$[0.0383]$} & {$[0.0143]$} & {$[0.0681]$} & {$[0.272]$} & {$[0.293]$} \\
\hline \multirow[t]{2}{*}{ Sobreocupado } & $0.230^{\star * *}$ & $0.197^{\star \star *}$ & $0.377^{\star \star *}$ & 0.0286 & $0.583^{\star \star}$ \\
\hline & {$[0.0383]$} & {$[0.0177]$} & {$[0.0712]$} & {$[0.260]$} & {$[0.263]$} \\
\hline \multirow[t]{2}{*}{ 3-6 meses } & $0.130^{\star *}$ & $-0.196^{\star \star \star}$ & 0.0777 & -0.00397 & $-0.772^{*}$ \\
\hline & {$[0.0637]$} & {$[0.0269]$} & {$[0.0747]$} & {$[0.396]$} & {$[0.407]$} \\
\hline \multirow[t]{2}{*}{ 6-1 año } & -0.0474 & $-0.264^{\star \star *}$ & -0.0586 & -0.498 & -0.218 \\
\hline & {$[0.0595]$} & {$[0.0255]$} & {$[0.0631]$} & {$[0.369]$} & {$[0.336]$} \\
\hline \multirow[t]{2}{*}{ 1-5 años } & $0.121^{\star *}$ & $0.389^{* * *}$ & $0.155^{\star \star}$ & -0.433 & -0.406 \\
\hline & {$[0.0472]$} & {$[0.0217]$} & {$[0.0660]$} & {$[0.312]$} & {$[0.264]$} \\
\hline \multirow[t]{2}{*}{ Más de 5 años } & $0.119^{\star *}$ & $0.397^{\star \star \star}$ & $0.235^{\star \star \star}$ & -0.263 & -0.180 \\
\hline & [0.0509] & {$[0.0234]$} & {$[0.0679]$} & [0.329] & [0.305] \\
\hline \multirow[t]{2}{*}{ Constante } & $-0.818^{\star \star \star}$ & $-0.475^{\star \star \star}$ & $-1.569^{\star \star \star}$ & $-1.972^{\star \star \star}$ & $-2.896^{\star * *}$ \\
\hline & {$[0.0867]$} & {$[0.0352]$} & {$[0.150]$} & [0.642] & [0.563] \\
\hline Observaciones & 12,338 & 61,184 & 6,709 & 374 & 346 \\
\hline
\end{tabular}

Standard errors in brackets

${ }^{\star * \star} p<0.01,{ }^{* *} p<0.05,{ }^{*} p<0$. 
En Argentina y Brasil se corrobora que los trabajadores del sector público fueron formalizados más intensamente que los ocupados de otras ramas de actividad. Por el contrario, en ambos países, conjuntamente con Ecuador, los ocupados en la construcción se encuentran en la situación opuesta. En Paraguay y Perú esta dimensión no resultó estadísticamente significativa, luego de controlar por el resto de las características de los ocupados y de los puestos de trabajo.

Finalmente, los asalariados que contaban con mayor antigüedad inicial exhibieron las mayores probabilidades de transformarse en registrados en la seguridad social en Argentina, Brasil y Ecuador.

En resumen, aunque el proceso de formalización en el mismo puesto de trabajo tuvo lugar para todos los grupos de trabajadores analizados, su ritmo no ha sido homogéneo entre ellos. Aquellos en edades centrales, los hombres, los más calificados, quienes trabajan a tiempo completo, en las empresas más grandes y con mayor antigüedad en el puesto, son los que más se han beneficiado de esta mejora en las condiciones de trabajo. Ello ha tendido, por lo tanto, a ampliar la brecha de formalidad inicial observada entre los individuos definidos de acuerdo a estas categorías.

Dado que la formalidad laboral es principalmente el resultado de una decisión tomada por el empleador y que, como se muestra arriba, una gran parte del incremento de los puestos registrados se llevó a cabo mediante la formalización in situ de asalariados inicialmente informales, parece importante identificar los factores que pueden haber inducido a los empleadores a favorecer a los trabajadores que presentaban un "mejor" vector de características.

Un posible argumento se basa en la teoría de salarios de eficiencia (Stiglitz, 1974) en tanto el crecimiento de las vacantes puede elevar la tasa de renuncias -ya que los empleados buscarán mejores oportunidades de empleo- y aumentar consecuentemente los costos de rotación que deben enfrentar los empleadores. Además, cuanto mayor sea el nivel de inversión realizado por el empleador en la capacitación específica del trabajador, más elevados serán los costos en los que incurre la firma cuando éste renuncia. Estos costos implícitos tienden a crecer con la antigüedad ya que, en general, el capital humano específico se acumula con la duración en el puesto (Carpio el al 2011, Bassanini et al, 2005; Arulampalam et al. 2004), Asimismo, dado que el nivel de escolarización a menudo está altamente correlacionado con la calificación del puesto, y dada la complementariedad del capital humano específico con el general, los trabajadores más educados suelen ser los que más participan en las actividades de entrenamiento. En este contexto, los 
empleadores tendrán mayores incentivos para retenerlos, especialmente a aquellos con más experiencia en sus puestos. Una forma de hacerlo es ofreciéndoles mejores condiciones de trabajo, por ejemplo, a través de la formalización. Por lo tanto, esto podría ayudar a explicar por qué los empleados con niveles de educación y antigüedad más altos resultaron particularmente beneficiados por la registración laboral en la misma ocupación.

Una mayor eficacia de la inspección laboral puede ser otra fuente del aumento de la formalización in situ en tanto ello aumenta los costos potenciales de la falta de regularización de los asalariados. Dado que éstos aumentan con el nivel de los salarios, esta podría ser una explicación adicional para la mayor tasa de formalización de las personas con niveles de educación y antigüedad más altos. Finalmente, la mayor intensidad de formalización dentro de las grandes empresas también podría asociarse a los controles más estrictos a los que son generalmente sometidas estas firmas.

\subsection{Las caracteristicas de las transiciones hacia un puesto formal}

El segundo canal de formalización laboral es el ingreso a ocupaciones formales desde el desempleo, la inactividad o una ocupación no formal diferente a la actual. El cuadro 6 presenta los resultados de la descomposición de estos flujos, tal como fue detallada en la sección metodológica. La columna I muestra el stock de individuos no formales en la primera observación $\left(S_{i}\right)$, la columna II la frecuencia con la que salen de este estado inicial $\left(P\left(E_{i}\right)\right)$, la siguiente indica la intensidad con la que transitan a un trabajo formal $\left(P\left(E_{j} \mid E_{i}\right)\right)$ luego de salir del estado inicial, la columna IV da cuenta de la tasa de entrada a un trabajo formal $\left(P\left(E_{i j}\right)\right)$, siendo ésta la multiplicación de las dos primeras, y la última columna exhibe la contribución de cada grupo al proceso de formalización, mediado por un cambio de ocupación o estado laboral $\left(f_{i j} / F_{j}\right)$.

En todos los países (excepto en Brasil), la principal contribución a los nuevos puestos de trabajo formales proviene de individuos que eran asalariados no registrados, inactivos o desempleados (en ese orden) en la primera observación. En Brasil, los mayores ingresos a la formalidad provienen de la inactividad, el desempleo y la informalidad. 
Cuadro 6. Tránsitos hacia el puesto formal. Fuente: Estimaciones propias sobre las encuestas de hogares de los países bajo estudio

\section{Argentina}

\begin{tabular}{|c|c|c|c|c|c|}
\hline Características & $\begin{array}{c}\text { Composición } \\
\text { del empleo } \\
\text { no formal }\end{array}$ & $\begin{array}{l}\text { Tasa de } \\
\text { salida del } \\
\text { estado } \\
\text { inicial }\end{array}$ & $\begin{array}{l}\text { Probabilidad } \\
\text { condicional } \\
\text { de transitar a } \\
\text { un puesto } \\
\text { formal }\end{array}$ & $\begin{array}{c}\text { Tasa de } \\
\text { entrada a } \\
\text { un puesto } \\
\text { formal }\end{array}$ & $\begin{array}{l}\text { Contribución } \\
\text { al total de } \\
\text { entradas a un } \\
\text { puesto formal }\end{array}$ \\
\hline \multicolumn{6}{|l|}{ Categoría } \\
\hline Asal. No Reg & 49 & 51.5 & 9.5 & 4.9 & 71.7 \\
\hline Cuent. Profes. & 7 & 18.2 & 9.9 & 1.8 & 3.7 \\
\hline Cuent. No Prof. & 33 & 35.8 & 5.8 & 2.1 & 20.4 \\
\hline Patrones & 9 & 12.9 & 9.0 & 1.2 & 3.0 \\
\hline Fliar sin Rem. & 2 & 56.9 & 3.4 & 2.0 & 1.1 \\
\hline TOTAL & 100 & 40.7 & 8.2 & 3.3 & 100 \\
\hline \multicolumn{6}{|l|}{ Educación } \\
\hline HSI & 52 & 46.0 & 5.8 & 2.7 & 41.0 \\
\hline SC-TI & 34 & 40.9 & 10.9 & 4.4 & 45.8 \\
\hline TC & 14 & 20.2 & 15.9 & 3.2 & 13.2 \\
\hline TOTAL & 100 & 40.7 & 8.2 & 3.3 & 100 \\
\hline \multicolumn{6}{|l|}{ Género } \\
\hline Mujer & 47 & 47.9 & 5.7 & 2.7 & 38.1 \\
\hline Hombre & 53 & 34.4 & 11.3 & 3.9 & 61.9 \\
\hline TOTAL & 100 & 40.7 & 8.2 & 3.3 & 100 \\
\hline \multicolumn{6}{|l|}{ Edad } \\
\hline Menos de 25 & 16 & 67.1 & 10.1 & 6.8 & 33.1 \\
\hline $25-45$ & 50 & 38.4 & 9.3 & 3.6 & 53.2 \\
\hline Más de 45 & 34 & 31.2 & 4.3 & 1.3 & 13.7 \\
\hline TOTAL & 100 & 40.7 & 8.2 & 3.3 & 100 \\
\hline \multicolumn{6}{|l|}{ Tamaño de la firma } \\
\hline Menos de 6 ocup. & 82 & 40.6 & 6.5 & 2.7 & 64.9 \\
\hline 6-40 ocupados & 14 & 41.4 & 14.5 & 6.0 & 25.1 \\
\hline Más de 40 ocup. & 4 & 39.5 & 20.0 & 7.9 & 10.0 \\
\hline TOTAL & 100 & 40.7 & 8.2 & 3.3 & 100 \\
\hline \multicolumn{6}{|l|}{ Sector de actividad } \\
\hline Industria & 12 & 41.9 & 9.1 & 3.8 & 13.4 \\
\hline Construcción & 13 & 47.5 & 8.6 & 4.1 & 15.8 \\
\hline Comercio & 30 & 37.5 & 7.4 & 2.8 & 24.6 \\
\hline Transporte & 6 & 31.1 & 11.7 & 3.6 & 6.6 \\
\hline Serv. Financieros & 9 & 27.3 & 14.0 & 3.8 & 10.3 \\
\hline Serv. Personales & 5 & 29.3 & 12.2 & 3.6 & 5.6 \\
\hline Serv. Doméstico & 16 & 55.6 & 4.0 & 2.2 & 10.6 \\
\hline Sector público & 2 & 33.1 & 26.0 & 8.6 & 4.5 \\
\hline Otros sectores & 8 & 41.8 & 8.9 & 3.7 & 8.6 \\
\hline TOTAL & 100 & 40.7 & 8.2 & 3.3 & 100 \\
\hline \multicolumn{6}{|l|}{ Intensidad laboral } \\
\hline Ocupado a tiempo parcial & 41 & 54.4 & 6.5 & 3.5 & 43.1 \\
\hline Ocupado pleno & 22 & 35.4 & 9.7 & 3.4 & 22.8 \\
\hline Sobreocupado & 37 & 28.6 & 10.8 & 3.1 & 34.1 \\
\hline TOTAL & 100 & 40.7 & 8.2 & 3.3 & 100 \\
\hline \multicolumn{6}{|l|}{ Antigüedad } \\
\hline 1-3 meses & 16 & 74.6 & 8.3 & 6.2 & 29.0 \\
\hline 3-6 meses & 6 & 62.6 & 9.5 & 5.9 & 11.5 \\
\hline 6-1 año & 9 & 56.4 & 9.1 & 5.1 & 13.5 \\
\hline 1-5 años & 33 & 38.6 & 8.3 & 3.2 & 31.3 \\
\hline Más de 5 años & 36 & 20.2 & 6.7 & 1.4 & 14.8 \\
\hline TOTAL & 100 & 40.7 & 8.2 & 3.3 & 100 \\
\hline
\end{tabular}




\section{Brasil}

\begin{tabular}{|c|c|c|c|c|c|}
\hline Características & $\begin{array}{l}\text { Composición } \\
\text { del empleo } \\
\text { no formal }\end{array}$ & $\begin{array}{l}\text { Tasa de } \\
\text { salida del } \\
\text { estado } \\
\text { inicial }\end{array}$ & $\begin{array}{l}\text { Probabilidad } \\
\text { condicional } \\
\text { de transitar } \\
\text { a un puesto } \\
\text { formal }\end{array}$ & $\begin{array}{l}\text { Tasa de } \\
\text { entrada a } \\
\text { un puesto } \\
\text { formal }\end{array}$ & $\begin{array}{l}\text { Contribución } \\
\text { al total de } \\
\text { entradas a } \\
\text { un puesto } \\
\text { formal }\end{array}$ \\
\hline \multicolumn{6}{|l|}{ Categoría } \\
\hline Asal. No Reg & 43 & 41.7 & 25.1 & 10.5 & 72.3 \\
\hline Cuent. Profes. & 7 & 16.2 & 19.7 & 3.2 & 3.7 \\
\hline Cuent. No Prof. & 37 & 24.1 & 14.4 & 3.5 & 20.6 \\
\hline Patrones & 12 & 9.5 & 14.2 & 1.3 & 2.5 \\
\hline Fliarsin Rem. & 1 & 37.3 & 10.7 & 4.0 & 0.8 \\
\hline TOTAL & 100 & 29.6 & 21.0 & 6.2 & 100 \\
\hline \multicolumn{6}{|l|}{ Educación } \\
\hline HSI & 45 & 31.4 & 17.0 & 5.3 & 38.8 \\
\hline SC-TI & 38 & 33.0 & 24.6 & 8.1 & 49.5 \\
\hline TC & 17 & 16.9 & 25.3 & 4.3 & 11.7 \\
\hline TOTAL & 100 & 29.6 & 21.0 & 6.2 & 100 \\
\hline \multicolumn{6}{|l|}{ Género } \\
\hline Mujer & 47 & 33.0 & 16.9 & 5.6 & 42.0 \\
\hline Hombre & 53 & 26.5 & 25.5 & 6.7 & 58.0 \\
\hline TOTAL & 100 & 29.6 & 21.0 & 6.2 & 100 \\
\hline \multicolumn{6}{|l|}{ Edad } \\
\hline Menos de 25 & 16 & 57.4 & 27.4 & 15.7 & 39.9 \\
\hline $25-45$ & 40 & 26.8 & 25.0 & 6.7 & 43.1 \\
\hline Más de 45 & 44 & 22.1 & 10.7 & 2.4 & 17.0 \\
\hline TOTAL & 100 & 29.6 & 21.0 & 6.2 & 100 \\
\hline \multicolumn{6}{|l|}{ Tamaño de la firma } \\
\hline Menos de 6 ocup. & 70 & 25.8 & 16.1 & 4.2 & 47.0 \\
\hline 6-40 ocupados & 5 & 28.0 & 24.8 & 6.9 & 6.1 \\
\hline Más de 40 ocup. & 25 & 40.5 & 29.2 & 11.8 & 46.9 \\
\hline TOTAL & 100 & 29.6 & 21.0 & 6.2 & 100 \\
\hline \multicolumn{6}{|l|}{ Sector de actividad } \\
\hline Industria & 13 & 32.2 & 21.1 & 6.8 & 13.7 \\
\hline Construcción & 11 & 28.0 & 23.6 & 6.6 & 11.4 \\
\hline Comercio & 28 & 28.8 & 19.4 & 5.6 & 24.9 \\
\hline Transporte & 7 & 24.0 & 27.1 & 6.5 & 6.8 \\
\hline Serv. Financieros & 14 & 27.8 & 27.2 & 7.6 & 16.5 \\
\hline Serv. Personales & 3 & 43.7 & 27.7 & 12.1 & 6.0 \\
\hline Serv. Doméstico & 10 & 33.0 & 13.0 & 4.3 & 7.0 \\
\hline Sector público & 4 & 43.8 & 21.9 & 9.6 & 5.5 \\
\hline Otros sectores & 10 & 27.6 & 17.8 & 4.9 & 8.1 \\
\hline TOTAL & 100 & 30.0 & 21.1 & 6.3 & 100 \\
\hline \multicolumn{6}{|l|}{ Intensidad laboral } \\
\hline Ocupado a tiempo parcial & 29 & 41.0 & 17.4 & 7.1 & 32.8 \\
\hline Ocupado pleno & 41 & 28.7 & 24.2 & 6.9 & 45.7 \\
\hline Sobreocupado & 31 & 20.1 & 21.7 & 4.4 & 21.5 \\
\hline TOTAL & 100 & 29.6 & 21.0 & 6.2 & 100 \\
\hline \multicolumn{6}{|l|}{ Antigüedad } \\
\hline 1-3 meses & 10 & 70.7 & 27.1 & 19.2 & 30.3 \\
\hline 3-6 meses & 7 & 56.4 & 23.8 & 13.5 & 15.5 \\
\hline 6-1 año & 9 & 47.8 & 23.6 & 11.3 & 15.6 \\
\hline 1-5 años & 34 & 26.6 & 19.6 & 5.2 & 28.3 \\
\hline Más de 5 años & 41 & 13.5 & 11.6 & 1.6 & 10.3 \\
\hline TOTAL & 100 & 29.6 & 21.0 & 6.2 & 100 \\
\hline
\end{tabular}




\section{Ecuador}

\begin{tabular}{|c|c|c|c|c|c|}
\hline Características & $\begin{array}{l}\text { Composición } \\
\text { del empleo } \\
\text { no formal }\end{array}$ & $\begin{array}{l}\text { Tasa de } \\
\text { salida del } \\
\text { estado } \\
\text { inicial }\end{array}$ & $\begin{array}{l}\text { Probabilidad } \\
\text { condicional } \\
\text { de transitar a } \\
\text { un puesto } \\
\text { formal }\end{array}$ & $\begin{array}{c}\text { Tasa de } \\
\text { entrada a } \\
\text { un puesto } \\
\text { formal }\end{array}$ & $\begin{array}{l}\text { Contribución } \\
\text { al total de } \\
\text { entradas a } \\
\text { un puesto } \\
\text { formal }\end{array}$ \\
\hline \multicolumn{6}{|l|}{ Categoría } \\
\hline Asal. No Reg & 40 & 44.6 & 15.4 & 6.9 & 71.2 \\
\hline Cuent. Profes. & 4 & 27.1 & 18.7 & 5.1 & 4.6 \\
\hline Cuent. No Prof. & 40 & 30.5 & 5.2 & 1.6 & 16.5 \\
\hline Patrones & 8 & 14.0 & 9.6 & 1.3 & 2.6 \\
\hline Fliar sin Rem. & 8 & 41.8 & 5.6 & 2.3 & 5.0 \\
\hline TOTAL & 100 & 35.7 & 10.9 & 3.9 & 100 \\
\hline \multicolumn{6}{|l|}{ Educación } \\
\hline HSI & 55 & 33.0 & 6.1 & 2.0 & 29.0 \\
\hline SC-TI & 36 & 41.4 & 14.8 & 6.1 & 57.3 \\
\hline TC & 8 & 28.9 & 22.2 & 6.4 & 13.7 \\
\hline TOTAL & 100 & 35.7 & 10.9 & 3.9 & 100 \\
\hline \multicolumn{6}{|l|}{ Género } \\
\hline Mujer & 42 & 46.0 & 6.8 & 3.1 & 33.8 \\
\hline Hombre & 58 & 28.3 & 15.8 & 4.5 & 66.2 \\
\hline TOTAL & 100 & 35.7 & 10.9 & 3.9 & 100 \\
\hline \multicolumn{6}{|l|}{ Edad } \\
\hline Menos de 25 & 17 & 65.0 & 12.5 & 8.2 & 35.5 \\
\hline $25-45$ & 51 & 33.5 & 12.5 & 4.2 & 55.2 \\
\hline Más de 45 & 32 & 23.7 & 4.8 & 1.1 & 9.3 \\
\hline TOTAL & 100 & 35.7 & 10.9 & 3.9 & 100 \\
\hline \multicolumn{6}{|l|}{ Tamaño de la firma } \\
\hline Menos de 6 ocup. & 80 & 34.2 & 7.8 & 2.7 & 55.1 \\
\hline 6-40 ocupados & 14 & 39.0 & 18.8 & 7.3 & 27.4 \\
\hline Más de 40 ocup. & 5 & 49.8 & 25.0 & 12.5 & 17.5 \\
\hline TOTAL & 100 & 35.7 & 10.9 & 3.9 & 100 \\
\hline \multicolumn{6}{|l|}{ Sector de actividad } \\
\hline Industria & 14 & 32.4 & 13.5 & 4.4 & 15.4 \\
\hline Construcción & 10 & 28.3 & 12.2 & 3.4 & 8.6 \\
\hline Comercio & 40 & 36.0 & 8.6 & 3.1 & 32.2 \\
\hline Transporte & 10 & 27.0 & 13.1 & 3.5 & 9.3 \\
\hline Serv. Financieros & 5 & 45.9 & 17.3 & 7.9 & 10.7 \\
\hline Serv. Personales & 4 & 40.5 & 13.1 & 5.3 & 5.1 \\
\hline Serv. Doméstico & 4 & 53.9 & 4.2 & 2.3 & 2.2 \\
\hline Sector público & 1 & 44.1 & 32.7 & 14.4 & 3.8 \\
\hline Otros sectores & 13 & 39.6 & 9.9 & 3.9 & 12.6 \\
\hline TOTAL & 100 & 35.7 & 10.8 & 3.9 & 100 \\
\hline \multicolumn{6}{|l|}{ Intensidad laboral } \\
\hline Ocupado a tiempo parcial & 26 & 55.3 & 7.1 & 3.9 & 25.9 \\
\hline Ocupado pleno & 35 & 33.2 & 13.9 & 4.6 & 41.3 \\
\hline Sobreocupado & 39 & 25.1 & 12.8 & 3.2 & 32.8 \\
\hline TOTAL & 100 & 35.7 & 10.9 & 3.9 & 100 \\
\hline \multicolumn{6}{|l|}{ Antigüedad } \\
\hline 1-3 meses & 25 & 67.7 & 14.6 & 9.8 & 63.4 \\
\hline 3-6 meses & 9 & 42.3 & 9.7 & 4.1 & 9.3 \\
\hline 6-1 año & 19 & 34.7 & 8.3 & 2.9 & 14.4 \\
\hline 1-5 años & 19 & 23.1 & 6.6 & 1.5 & 7.3 \\
\hline Más de 5 años & 28 & 14.4 & 5.4 & 0.8 & 5.6 \\
\hline TOTAL & 100 & 35.7 & 10.9 & 3.9 & 100 \\
\hline
\end{tabular}




\begin{tabular}{|c|c|c|c|c|c|}
\hline Características & $\begin{array}{l}\text { Composición } \\
\text { del empleo } \\
\text { no formal }\end{array}$ & $\begin{array}{l}\text { Tasa de } \\
\text { salida del } \\
\text { estado } \\
\text { inicial }\end{array}$ & $\begin{array}{l}\text { Probabilidad } \\
\text { condicional } \\
\text { de transitar a } \\
\text { un puesto } \\
\text { formal }\end{array}$ & $\begin{array}{c}\text { Tasa de } \\
\text { entrada a } \\
\text { un puesto } \\
\text { formal }\end{array}$ & $\begin{array}{l}\text { Contribución } \\
\text { al total de } \\
\text { entradas a un } \\
\text { puesto } \\
\text { formal }\end{array}$ \\
\hline \multicolumn{6}{|l|}{ Categoría } \\
\hline Asal. No Reg & 52 & 51.2 & 7.0 & 3.6 & 81.5 \\
\hline Cuent. Profes. & 1 & 28.1 & 28.8 & 8.1 & 5.2 \\
\hline Cuent. No Prof. & 32 & 36.4 & 1.1 & 0.4 & 5.7 \\
\hline Patrones & 10 & 12.8 & 0.0 & 0.0 & 0.0 \\
\hline Fliarsin Rem. & 5 & 52.7 & 7.1 & 3.7 & 7.6 \\
\hline TOTAL & 100 & 42.5 & 5.4 & 2.3 & 100 \\
\hline \multicolumn{6}{|l|}{ Educación } \\
\hline HSI & 57 & 45.8 & 2.3 & 1.0 & 25.8 \\
\hline SC-TI & 40 & 39.4 & 9.8 & 3.9 & 66.5 \\
\hline TC & 3 & 18.6 & 32.3 & 6.0 & 7.7 \\
\hline TOTAL & 100 & 42.5 & 5.4 & 2.3 & 100 \\
\hline \multicolumn{6}{|l|}{ Género } \\
\hline Mujer & 46 & 44.9 & 6.5 & 2.9 & 58.3 \\
\hline Hombre & 54 & 40.4 & 4.4 & 1.8 & 41.7 \\
\hline TOTAL & 100 & 42.5 & 5.4 & 2.3 & 100 \\
\hline \multicolumn{6}{|l|}{ Edad } \\
\hline Menos de 25 & 25 & 64.0 & 5.9 & 3.8 & 40.4 \\
\hline $25-45$ & 45 & 38.0 & 6.5 & 2.5 & 47.8 \\
\hline Más de 45 & 30 & 31.6 & 2.8 & 0.9 & 11.8 \\
\hline TOTAL & 100 & 42.5 & 5.4 & 2.3 & 100 \\
\hline \multicolumn{6}{|l|}{ Tamaño de la firma } \\
\hline Menos de 6 ocup. & 74 & 41.9 & 3.6 & 1.5 & 48.5 \\
\hline 6-40 ocupados & 18 & 46.7 & 9.9 & 4.6 & 35.9 \\
\hline Más de 40 ocup. & 8 & 37.9 & 11.6 & 4.4 & 15.5 \\
\hline TOTAL & 100 & 42.5 & 5.4 & 2.3 & 100 \\
\hline \multicolumn{6}{|l|}{ Sector de actividad } \\
\hline Industria & 12 & 38.3 & 3.1 & 1.2 & 6.2 \\
\hline Construcción & 10 & 57.1 & 2.3 & 1.3 & 5.8 \\
\hline Comercio & 38 & 37.2 & 5.7 & 2.1 & 34.5 \\
\hline Transporte & 4 & 42.6 & 8.0 & 3.4 & 6.1 \\
\hline Serv. Financieros & 6 & 41.6 & 16.5 & 6.9 & 16.8 \\
\hline Serv. Personales & 17 & 41.0 & 6.5 & 2.6 & 19.4 \\
\hline Serv. Doméstico & 11 & 57.4 & 4.2 & 2.4 & 11.3 \\
\hline Sector público & 2 & 29.1 & 0.0 & 0.0 & 0.0 \\
\hline Otros sectores & o & & & & 0.0 \\
\hline TOTAL & 100 & 42.5 & 5.4 & 2.3 & 100 \\
\hline \multicolumn{6}{|l|}{ Intensidad laboral } \\
\hline Ocupado a tiempo parcial & 29 & 53.7 & 4.1 & 2.2 & 27.9 \\
\hline Ocupado pleno & 19 & 42.5 & 7.1 & 3.0 & 25.3 \\
\hline Sobreocupado & 51 & 36.0 & 5.9 & 2.1 & 46.8 \\
\hline TOTAL & 100 & 42.5 & 5.4 & 2.3 & 100 \\
\hline \multicolumn{6}{|l|}{ Antigüedad } \\
\hline 1-3 meses & 15 & 78.4 & 6.2 & 4.9 & 31.9 \\
\hline 3-6 meses & 7 & 60.5 & 9.2 & 5.5 & 16.6 \\
\hline 6-1 año & 12 & 51.7 & 2.7 & 1.4 & 7.2 \\
\hline 1-5 años & 30 & 36.0 & 5.3 & 1.9 & 25.4 \\
\hline Más de 5 años & 36 & 26.2 & 4.7 & 1.2 & 18.9 \\
\hline TOTAL & 100 & 42.5 & 5.4 & 2.3 & 100 \\
\hline
\end{tabular}




\begin{tabular}{|c|c|c|c|c|c|}
\hline Características & $\begin{array}{l}\text { Composición } \\
\text { del empleo } \\
\text { no formal }\end{array}$ & $\begin{array}{l}\text { Tasa de } \\
\text { salida del } \\
\text { estado } \\
\text { inicial }\end{array}$ & $\begin{array}{l}\text { Probabilidad } \\
\text { condicional } \\
\text { de transitar } \\
\text { a un puesto } \\
\text { formal }\end{array}$ & $\begin{array}{c}\text { Tasa de } \\
\text { entrada a } \\
\text { un puesto } \\
\text { formal }\end{array}$ & $\begin{array}{l}\text { Contribución } \\
\text { al total de } \\
\text { entradas a } \\
\text { un puesto } \\
\text { formal }\end{array}$ \\
\hline \multicolumn{6}{|l|}{ Categoría } \\
\hline Asal. No Reg & 38 & 64.0 & 9.8 & 6.3 & 56.9 \\
\hline Cuent. Profes. & 6 & 37.6 & 25.8 & 9.7 & 13.6 \\
\hline Cuent. No Prof. & 41 & 36.5 & 6.0 & 2.2 & 21.3 \\
\hline Patrones & 7 & 20.7 & 10.3 & 2.1 & 3.5 \\
\hline Fliarsin Rem. & 8 & 58.6 & 4.1 & 2.4 & 4.8 \\
\hline TOTAL & 100 & 47.8 & 8.8 & 4.2 & 100 \\
\hline \multicolumn{6}{|l|}{ Educación } \\
\hline HSI & 38 & 43.8 & 4.8 & 2.1 & 19.0 \\
\hline SC-TI & 48 & 52.9 & 8.0 & 4.2 & 47.5 \\
\hline TC & 14 & 41.8 & 23.5 & 9.8 & 33.5 \\
\hline TOTAL & 100 & 47.8 & 8.8 & 4.2 & 100 \\
\hline \multicolumn{6}{|l|}{ Género } \\
\hline Mujer & 52 & 50.3 & 4.6 & 2.3 & 28.3 \\
\hline Hombre & 48 & 45.2 & 13.8 & 6.2 & 71.7 \\
\hline TOTAL & 100 & 47.8 & 8.8 & 4.2 & 100 \\
\hline \multicolumn{6}{|l|}{ Edad } \\
\hline Menos de 25 & 23 & 74.4 & 5.4 & 4.0 & 22.4 \\
\hline $25-45$ & 49 & 46.0 & 11.2 & 5.1 & 59.6 \\
\hline Más de 45 & 28 & 28.6 & 9.6 & 2.7 & 18.0 \\
\hline TOTAL & 100 & 47.8 & 8.8 & 4.2 & 100 \\
\hline \multicolumn{6}{|l|}{ Tamaño de la firma } \\
\hline Menos de 6 ocup. & 80 & 45.1 & 7.2 & 3.2 & 61.2 \\
\hline 6-40 ocupados & 14 & 59.1 & 12.3 & 7.3 & 23.7 \\
\hline Más de 40 ocup. & 7 & 57.9 & 16.8 & 9.7 & 15.2 \\
\hline TOTAL & 100 & 47.8 & 8.8 & 4.2 & 100 \\
\hline \multicolumn{6}{|l|}{ Sector de actividad } \\
\hline Industria & 13 & 51.5 & 5.7 & 2.9 & 9.2 \\
\hline Construcción & 6 & 54.9 & 16.6 & 9.1 & 13.3 \\
\hline Comercio & 40 & 44.1 & 6.5 & 2.9 & 27.3 \\
\hline Transporte & 13 & 35.4 & 12.0 & 4.2 & 13.2 \\
\hline Serv. Financieros & 5 & 55.6 & 14.6 & 8.1 & 8.9 \\
\hline Serv. Personales & 4 & 55.1 & 12.2 & 6.7 & 7.2 \\
\hline Serv. Doméstico & 5 & 58.7 & 3.7 & 2.2 & 2.7 \\
\hline Sector público & 3 & 55.5 & 12.4 & 6.9 & 4.2 \\
\hline Otros sectores & 10 & 55.1 & 10.2 & 5.6 & 14.0 \\
\hline TOTAL & 100 & 47.8 & 8.8 & 4.2 & 100 \\
\hline \multicolumn{6}{|l|}{ Intensidad laboral } \\
\hline Ocupado a tiempo parcial & 36 & 63.0 & 7.6 & 4.8 & 40.7 \\
\hline Ocupado pleno & 14 & 47.1 & 5.9 & 2.8 & 9.4 \\
\hline Sobreocupado & 50 & 37.1 & 11.4 & 4.2 & 49.9 \\
\hline TOTAL & 100 & 47.8 & 8.8 & 4.2 & 100 \\
\hline \multicolumn{6}{|l|}{ Antigüedad } \\
\hline 1-3 meses & 22 & 80.1 & 10.2 & 8.1 & 43.1 \\
\hline 3-6 meses & 7 & 66.0 & 7.2 & 4.8 & 8.0 \\
\hline 6-1 año & 10 & 60.4 & 9.1 & 5.5 & 13.5 \\
\hline 1-5 años & 30 & 41.5 & 8.1 & 3.4 & 23.7 \\
\hline Más de 5 años & 30 & 21.8 & 7.3 & 1.6 & 11.6 \\
\hline TOTAL & 100 & 47.8 & 8.8 & 4.2 & 100 \\
\hline
\end{tabular}


En el caso de individuos inactivos, su alta contribución se deriva principalmente del hecho de que representan un grupo relativamente grande entre los trabajadores inicialmente no formales. Por el contrario, el grupo de desempleados, aunque menor en número, exhibe tasas de salida más altas de ese estado y mayores chances de transitar a la formalidad después de salir del desempleo, en comparación con los inactivos. Finalmente, la mayor importancia de los asalariados no registrados en este tipo de flujos respecto de la de los desempleados resulta exclusivamente de su mayor tamaño ya que exhiben tasas de retención más altas y, adicionalmente, se dirigen con menor intensidad a la formalidad luego de abandonar su estado inicial.

Este hallazgo respecto de las menores chances de transitar hacia la formalidad que exhiben los asalariados no registrados en comparación con la de los desocupados es particularmente relevante en el contexto de la discusión acerca del papel de aquellos en la carrera ocupacional de las personas. Suele señalarse que la informalidad constituye un trampolín hacia la formalidad, en tanto aumenta el capital humano de los trabajadores ${ }^{9}$, lo que les proporcionaría una mejor información sobre las vacantes de empleo. Ambos factores darían lugar a que los trabajadores informales tengan una mayor probabilidad de transitar a la formalidad que los desempleados. Sin embargo, los resultados recién discutidos no apoyan este argumento y, por el contrario, sugerirían que la informalidad produce un mayor efecto "cicatriz" que el desempleo. Pero también podría ser el resultado de un efecto composición, dado que la falta de seguro de desempleo en los países en desarrollo significa que las personas que permanecen desempleadas tendrían, al menos en parte, mayor capacidad, respecto de los trabajadores informales, para encarar una búsqueda prolongada que le permita finalmente acceder a un empleo de calidad, por ejemplo, uno formal. Este es ciertamente un asunto que necesita ser explorado más a fondo en futuras investigaciones (Cazes y Verick, 2013).

En todos los países, y al igual que lo observado en el caso de la formalización in situ, las personas con un nivel educativo intermedio contribuyen en mayor medida a las transiciones entre la no formalidad y la formalidad. La menor contribución de los trabajadores con educación universitaria a estas transiciones se explica principalmente por su menor importancia numérica y, en Argentina, Brasil y Paraguay, también por

\footnotetext{
${ }^{9}$ Este argumento es similar al esgrimido en el caso de los trabajadores temporarios, donde este tipo de ocupaciones serían un trampolín hacia una posición permanente (Booth et al., 2002; Zijl et al., 2009). Sin embargo, la evidencia no siempre confirma este argumento (Carpio et al., 2011).
} 
sus más reducidas chances de abandonar el estado inicial. Como ya se mencionó, los trabajadores con educación superior generalmente reciben más capacitación, y esto hace que los empleadores intenten retenerlos, lo que resulta en tasas de salida relativamente más bajas para este grupo.

Sin embargo, en todos los casos, una vez que han salido de un trabajo no formal, éstos transitan con mayor frecuencia que el resto de los individuos hacia una ocupación registrada. Este hallazgo es confirmado por las estimaciones probit donde la variable dependiente toma el valor 1 si el individuo transita hacia la formalidad una vez abandonado el puesto inicial y 0 en caso contrario. Los resultados son presentados en el cuadro 7. Allí se observa que la probabilidad condicional es creciente con el nivel educativo. Ello puede deberse tanto a factores de demanda como de oferta. En el primer caso, es evidente en toda la región la asociación positiva entre formalidad y nivel educativo lo que se traduce en mayores tasas de entrada de los individuos con mayor capital humano general a este tipo de puestos (Bertranou, 2013; Beccaria et al., 2015a; Amarante y Arim, 2015). En el segundo caso, esta evidencia podría estar dando cuenta de que los trabajadores de mayor nivel educativo cuentan con mayores recursos financieros para realizar una búsqueda de empleo que redunde en la obtención de un puesto de mejores características, entre las cuales se encuentran las posiciones formales.

Las diferencias entre mujeres y hombres son más significativas en lo que hace a estas transiciones que en el caso de la formalización en la misma ocupación; en particular, se evidencian tasas de ingreso más altas a empleos formales entre los hombres. Esto se explica principalmente por sus mayores chances de transitar a la formalidad después de abandonar el estado inicial. Tal resultado, que también es corroborado a partir de las regresiones probit (excepto en Paraguay) presentadas en el cuadro 7, está en línea con los encontrados en la literatura internacional que sugieren que las mujeres tienen mayores dificultades para obtener un trabajo formal que los hombres. ${ }^{10}$

10 Véase, por ejemplo, Blau et al. (2002), Cerruti (2000). 
Cuadro 7. Regresiones probit. Probabilidad condicional de entrar a un puesto formal.

\begin{tabular}{|c|c|c|c|c|c|}
\hline Covariables & ARGENTINA & BRASIL & ECUADOR & PARAGUAY & PERU \\
\hline SC-TI & $\begin{array}{c}0.169^{* * *} \\
{[0.0327]}\end{array}$ & $\begin{array}{c}0.111^{* * *} \\
{[0.0143]}\end{array}$ & $\begin{array}{c}0.382^{* * *} \\
{[0.0481]}\end{array}$ & $\begin{array}{c}0.335 \\
{[0.211]}\end{array}$ & $\begin{array}{c}0.679^{* * *} \\
{[0.254]}\end{array}$ \\
\hline TC & $\begin{array}{l}0.120^{\star \star} \\
{[0.0553]}\end{array}$ & $\begin{array}{c}0.170^{\star \star \star \star} \\
{[0.0207]}\end{array}$ & $\begin{array}{c}0.500^{\star \star \star} \\
{[0.0828]}\end{array}$ & $\begin{array}{l}-0.179 \\
{[0.598]}\end{array}$ & $\begin{array}{c}1.133^{\star \star \star} \\
{[0.305]}\end{array}$ \\
\hline Sexo & $\begin{array}{c}0.0869^{\star \star} \\
{[0.0391]}\end{array}$ & $\begin{array}{c}0.0475^{\star \star \star} \\
{[0.0142]}\end{array}$ & $\begin{array}{l}-0.0406 \\
{[0.0527]}\end{array}$ & $\begin{array}{l}0.269^{* *} \\
{[0.213]}\end{array}$ & $\begin{array}{l}0.295^{\star *} \\
{[0.221]}\end{array}$ \\
\hline $25-45$ & $\begin{array}{l}0.0446 \\
{[0.0407]}\end{array}$ & $\begin{array}{c}0.0459^{* * *} \\
{[0.0167]}\end{array}$ & $\begin{array}{l}0.0665 \\
{[0.0601]}\end{array}$ & $\begin{array}{l}0.374 \\
{[0.230]}\end{array}$ & $\begin{array}{c}0.238^{* *} \\
{[0.239]}\end{array}$ \\
\hline Más de 45 & $\begin{array}{l}0.0437 \\
{[0.0480]}\end{array}$ & $\begin{array}{l}0.135^{\star * *} \\
{[0.0184]}\end{array}$ & $\begin{array}{l}0.0861 \\
{[0.0734]}\end{array}$ & $\begin{array}{c}0.417 \\
{[0.315]}\end{array}$ & $\begin{array}{c}0.600^{* *} \\
{[0.298]}\end{array}$ \\
\hline 6-40 ocupados & $\begin{array}{l}0.468^{* * *} \\
{[0.0368]}\end{array}$ & $\begin{array}{l}0.377^{* * *} \\
{[0.0259]}\end{array}$ & $\begin{array}{l}0.591^{* * *} \\
{[0.0519]}\end{array}$ & $\begin{array}{c}0.595^{* * *} \\
{[0.228]}\end{array}$ & $\begin{array}{c}0.870^{* * *} \\
{[0.237]}\end{array}$ \\
\hline Más de 40 ocup. & $\begin{array}{l}0.648^{* * *} \\
{[0.0527]}\end{array}$ & $\begin{array}{c}0.597^{* * *} \\
{[0.0178]}\end{array}$ & $\begin{array}{l}1.099^{* * *} \\
{[0.0701]}\end{array}$ & $\begin{array}{c}0.775^{\star * *} \\
{[0.272]}\end{array}$ & $\begin{array}{c}1.126^{\star * *} \\
{[0.287]}\end{array}$ \\
\hline Industria & $\begin{array}{l}-0.565^{\star \star \star} \\
{[0.0742]}\end{array}$ & $\begin{array}{c}-0.434^{\star \star \star} \\
{[0.0264]}\end{array}$ & $\begin{array}{c}-0.260^{\star \star} \\
{[0.127]}\end{array}$ & $\begin{array}{l}0.0995 \\
{[0.495]}\end{array}$ & $\begin{array}{c}-0.0728 \\
{[0.382]}\end{array}$ \\
\hline Construcción & $\begin{array}{c}-0.768^{* * *} \\
{[0.0794]}\end{array}$ & $\begin{array}{c}-0.749^{* * *} \\
{[0.0354]}\end{array}$ & $\begin{array}{c}-0.914^{* * *} \\
{[0.139]}\end{array}$ & $\begin{array}{l}-0.891 \\
{[0.640]}\end{array}$ & $\begin{array}{l}0.705 \\
{[0.483]}\end{array}$ \\
\hline Comercio & $\begin{array}{c}-0.288^{\star * *} \\
{[0.0677]}\end{array}$ & $\begin{array}{c}-0.447^{\star \star *} \\
{[0.0250]}\end{array}$ & $\begin{array}{c}-0.258^{\star *} \\
{[0.125]}\end{array}$ & $\begin{array}{l}0.120 \\
{[0.478]}\end{array}$ & $\begin{array}{l}0.216 \\
{[0.380]}\end{array}$ \\
\hline Transporte & $\begin{array}{l}-0.724^{* * *} \\
{[0.0796]}\end{array}$ & $\begin{array}{c}-0.505^{\star * *} \\
{[0.0335]}\end{array}$ & $\begin{array}{c}-0.314^{\star \star} \\
{[0.137]}\end{array}$ & $\begin{array}{l}0.152 \\
{[0.560]}\end{array}$ & $\begin{array}{c}0.0460 \\
{[0.396]}\end{array}$ \\
\hline Serv. Financieros & $\begin{array}{c}-0.282^{* * *} \\
{[0.0780]}\end{array}$ & $\begin{array}{c}-0.473^{\star * *} \\
{[0.0239]}\end{array}$ & $\begin{array}{l}0.255^{\star} \\
{[0.150]}\end{array}$ & $\begin{array}{c}0.121 \\
{[0.546]}\end{array}$ & $\begin{array}{l}0.309 \\
{[0.453]}\end{array}$ \\
\hline Serv. Personales & $\begin{array}{c}-0.288^{* * *} \\
{[0.0786]}\end{array}$ & $\begin{array}{c}-0.274^{* * *} \\
{[0.0267]}\end{array}$ & $\begin{array}{l}0.143 \\
{[0.135]}\end{array}$ & $\begin{array}{l}-0.146 \\
{[0.499]}\end{array}$ & $\begin{array}{l}0.280 \\
{[0.447]}\end{array}$ \\
\hline Serv. Doméstico & $\begin{array}{c}-0.599^{* * *} \\
{[0.0733]}\end{array}$ & $\begin{array}{c}-0.446^{* * *} \\
{[0.0292]}\end{array}$ & $\begin{array}{c}0.222 \\
{[0.148]}\end{array}$ & & \\
\hline Otros sectores & $\begin{array}{c}-0.367^{\star \star \star} \\
{[0.0790]}\end{array}$ & $\begin{array}{c}-0.770^{\star \star \star} \\
{[0.0282]}\end{array}$ & $\begin{array}{c}-0.535^{\star \star \star} \\
{[0.125]}\end{array}$ & & $\begin{array}{l}-0.342 \\
{[0.443]}\end{array}$ \\
\hline Ocupado pleno & $\begin{array}{l}0.246^{* * *} \\
{[0.0383]}\end{array}$ & $\begin{array}{c}0.287^{* * *} \\
{[0.0143]}\end{array}$ & $\begin{array}{c}0.355^{\star * *} \\
{[0.0681]}\end{array}$ & $\begin{array}{l}0.0663 \\
{[0.272]}\end{array}$ & $\begin{array}{l}0.521^{*} \\
{[0.293]}\end{array}$ \\
\hline Sobreocupado & $\begin{array}{c}0.230^{\star \star * \star} \\
{[0.0383]}\end{array}$ & $\begin{array}{c}0.197^{\star * *} \\
{[0.0177]}\end{array}$ & $\begin{array}{l}0.377^{\star * \star} \\
{[0.0712]}\end{array}$ & $\begin{array}{l}0.0286 \\
{[0.260]}\end{array}$ & $\begin{array}{l}0.583^{* *} \\
{[0.263]}\end{array}$ \\
\hline 3-6 meses & $\begin{array}{l}0.130^{\star \star} \\
{[0.0637]}\end{array}$ & $\begin{array}{l}-0.196^{\star * *} \\
{[0.0269]}\end{array}$ & $\begin{array}{l}0.0777 \\
{[0.0747]}\end{array}$ & $\begin{array}{c}-0.00397 \\
{[0.396]}\end{array}$ & $\begin{array}{c}-0.772^{*} \\
{[0.407]}\end{array}$ \\
\hline 6-1 año & $\begin{array}{l}-0.0474 \\
{[0.0595]}\end{array}$ & $\begin{array}{c}-0.264^{* * *} \\
{[0.0255]}\end{array}$ & $\begin{array}{l}-0.0586 \\
{[0.0631]}\end{array}$ & $\begin{array}{l}-0.498 \\
{[0.369]}\end{array}$ & $\begin{array}{l}-0.218 \\
{[0.336]}\end{array}$ \\
\hline 1-5 años & $\begin{array}{l}0.121^{* *} \\
{[0.0472]}\end{array}$ & $\begin{array}{c}0.389^{* * *} \\
{[0.0217]}\end{array}$ & $\begin{array}{l}0.155^{\star *} \\
{[0.0660]}\end{array}$ & $\begin{array}{l}-0.433 \\
{[0.312]}\end{array}$ & $\begin{array}{l}-0.406 \\
{[0.264]}\end{array}$ \\
\hline Más de 5 años & $\begin{array}{l}0.119^{* *} \\
{[0.0509]}\end{array}$ & $\begin{array}{c}0.397^{* * *} \\
{[0.0234]}\end{array}$ & $\begin{array}{c}0.235^{\star * *} \\
{[0.0679]}\end{array}$ & $\begin{array}{l}-0.263 \\
{[0.329]}\end{array}$ & $\begin{array}{l}-0.180 \\
{[0.305]}\end{array}$ \\
\hline Constante & $\begin{array}{l}-0.818^{\star * *} \\
{[0.0867]}\end{array}$ & $\begin{array}{c}-0.475^{\star * *} \\
{[0.0352]}\end{array}$ & $\begin{array}{c}-1.569^{* * *} \\
{[0.150]}\end{array}$ & $\begin{array}{c}-1.972^{\star * *} \\
{[0.642]}\end{array}$ & $\begin{array}{c}-2.896^{* * *} \\
{[0.563]}\end{array}$ \\
\hline Observaciones & 12,338 & 61,184 & 6,709 & 374 & 346 \\
\hline
\end{tabular}


Los jóvenes son los que experimentan con mayor intensidad los tránsitos hacia la formalidad. En todos los casos, ello se explica principalmente por la mayor inestabilidad en su posición inicial. La mayor rotación de los jóvenes en el mercado de trabajo es un resultado frecuentemente encontrado tanto en la literatura internacional como, en particular, en América Latina. Allí se mencionan múltiples explicaciones para este resultado. Por el lado de la oferta, los niveles más altos de rotación están asociados con las características de los jóvenes o con una decisión de su parte de acceder a trabajos que terminan siendo más inestables pero que tienen otras cualidades por ellos valoradas. Por el lado de la demanda, la alta rotación puede también estar asociada con la segregación ocupacional que experimentan por parte de los empleadores quienes consideran que los jóvenes son menos confiables. ${ }^{11}$

Las personas que trabajaban en grandes empresas en la observación inicial transitan con mayor frecuencia hacia un puesto formal en relación a aquellos que trabajan en empresas chicas o medianas Cabe destacar que una parte significativa de los trabajadores informales de grandes empresas transitaron a otra gran empresa después de abandonar el puesto inicial. Por lo tanto, estas transiciones pueden estar asociadas con el hecho de que las tasas de formalidad son más altas en este tipo de empresa en comparación con el resto. ${ }^{12}$ Además, es probable que los trabajadores de las grandes compañías tengan una red social más amplia que aquellos que se desempeñan en las de menor tamaño y ello les brinde más información sobre oportunidades de empleo en otras compañías con las mismas características. Por último, podría existir un efecto de "señalización" (signalling) según el cual los futuros empleadores podrían considerar a los trabajadores de grandes empresas como más adecuados para ocupar un puesto formal. Las estimaciones econométricas confirman la correlación positiva entre tamaño de la empresa y probabilidad condicional de transitar hacia la formalidad en Argentina, Brasil y Ecuador.

Finalmente, y a diferencia del proceso de formalización in situ, los trabajadores con baja antigüedad han hecho la mayor contribución a los flujos entre informalidad y formalidad en la mayoría de los países considerados. Esto se debe a dos razones: por un lado, a que una mayor duración en el trabajo reduce las tasas de salida; ${ }^{13}$ sin embargo, de

\footnotetext{
${ }^{11}$ Cunningham y Salvagno (2011), Beccaria y Maurizio (2018).

12 FORLAC (2014).

${ }^{13}$ Esta relación negativa entre la duración y las probabilidades de salir de una ocupación es frecuentemente encontrada en la literatura internacional. Véase, por ejemplo, Farber (1999), Blau y Kahn, (1981), Mincer y Jovanovic (1981).
} 
acuerdo a las estimaciones probit, la antigüedad en el puesto no resulta ser una variable significativa para explicar la probabilidad condicional de dirigirse a un puesto luego de abandonar la ocupación inicial. Sólo en Brasil se observa una correlación negativa entre ambas variables. Este último patrón es realmente llamativo y podría también asociarse a la hipótesis del efecto cicatriz en tanto el paso por la informalidad reduzca las posibilidades de obtener un empleo formal; en tal caso, resulta esperable que las posibilidades de acceder a un puesto registrado disminuyan a medida que aumenta la duración del episodio de informalidad. ${ }^{14}$

\section{Los factores asociados al proceso de formalización laboral. Evidencia empírica para los países bajo estudio}

Como fue mencionado previamente, el aumento de la formalidad laboral en América Latina durante los 2000 no respondería a un único determinante, sino que parece haber requerido de la combinación de diversos factores de diferente naturaleza. En particular, este proceso debió haber demandado como condición necesaria un contexto macroeconómico de crecimiento estable. En este marco, las políticas que tienden a un mayor control del cumplimiento de la normativa laboral y aquellas que generan incentivos a la registración contribuyen a que tal proceso finalmente se verifique. A continuación se analiza la evidencia empírica sobre estos factores para los países bajo análisis.

\subsection{El contexto macroeconómico. La relevancia del crecimiento estable con generación de empleo}

Como se mencionó en la sección 5, América Latina inició a principios de la década de 2000 un período de expansión económica alta y sostenida. En este contexto, los países de América Latina considerados aquí experimentaron dinámicas del PIB y el empleo similares a las del resto de la región, mientras que el desempleo y la informalidad fueron contracíclicos (gráfico 2). Esto está en marcado contraste con las tendencias de la década de 1990, cuando aumentaron la tasa de desempleo y la informalidad.

\footnotetext{
${ }^{14}$ Beccaria et al. (2016), Cruces et al. (2012), Gally y Kucer (2003).
} 
Gráfico 2. Evolución del PIB, desempleo e informalidad. Fuente: Estimaciones propias sobre la base de datos de la CEPAL y de las encuestas de hogares de los países bajo estudio.
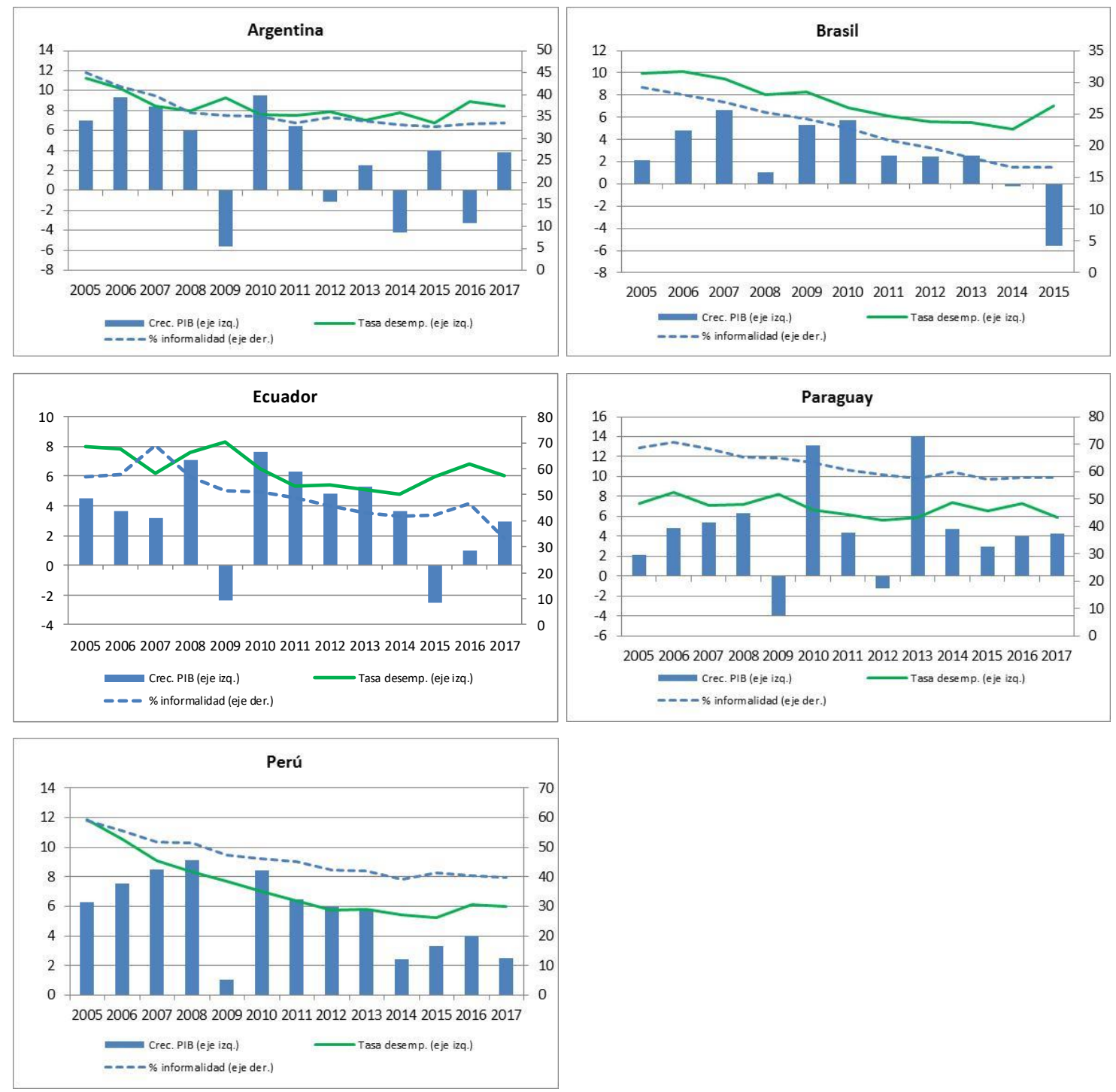
Existen algunos estudios empíricos que intentan estimar el impacto del ciclo económico sobre la formalidad. Por ejemplo, Bosch y Esteban-Pretel (2009) lo hacen a partir de un modelo de búsqueda y matching donde los empleadores pueden elegir contratar a un asalariado de manera formal o de manera informal. En el primer caso, las empresas pueden aprovechar al máximo la productividad del matching pero tienen que afrontar el costo de cumplir con las regulaciones laborales. En el segundo caso, las empresas evitan estos costos pero serán penalizadas si se detectan en infracción. El modelo predice que en los períodos de crecimiento las firmas contratarán más intensamente trabajadores formales de modo de aprovechar la mayor productividad asociada a este tipo de contratos. Asimismo, la tasa de destrucción de ambos tipos de puestos de trabajo, formales e informales, se reduce y por lo tanto el desempleo disminuye. Los autores comprueban la validez de estas predicciones en Brasil durante el período 1983-2001. Bajo una perspectiva similar, Boeri y Garibaldi (2007) predicen una correlación positiva entre desempleo e informalidad.

Corsueil y Foguel (2012) también sugieren un comportamiento procíciclo de la formalidad. Para ello modelan los tránsitos no sólo entre formalidad e informalidad sino entre ellos y el desempleo en las fases expansivas del ciclo. Se asume que los desocupados tienen un salario de reserva inferior al de los trabajadores informales. Por lo tanto cuando el pool de desocupados es elevado, las empresas obtienen trabajadores provenientes de allí ofreciendo bajos salarios. Inicialmente, éstos encuentran trabajo con mayor probabilidad en empresas pequeñas (y con menores niveles de productividad), ya que éstas son más numerosas que las empresas grandes. Se supone, también, que las firmas sólo ofrecen un tipo de puesto, formal (empresas grandes) o informal (empresas pequeñas). Por lo tanto, el empleo en firmas pequeñas crece en los primeros momentos de la recuperación. Sin embargo, estos trabajadores siguen buscando un mejor empleo entre las firmas grandes debido a los salarios más elevados que éstas ofrecen. Por lo tanto, a medida que el desempleo cae en la fase creciente del ciclo la probabilidad de transitar desde la informalidad a la formalidad aumenta con el consecuente incremento en el porcentaje de trabajadores formales. Esta predicción también es confirmada para el caso de Brasil en los años 2003-2008.

Finalmente, como fue comentado, desde el punto de vista de los trabajadores, el crecimiento del empleo y la reducción del desempleo otorgan a los individuos una mayor capacidad de negociación frente a sus empleadores a la vez que incrementa el salario de reserva, lo que también puede contribuir a un mejoramiento de las condiciones laborales con 
impactos positivos sobre la registración. Arias y Sosa Escudero (2007) evalúan la relación entre informalidad, brecha salarial entre asalariados formales e informales y desempleo en Argentina para el período 19852003. Para ello utilizan métodos del Panel VAR y encuentran evidencia que apoya el argumento de que los trabajadores ingresan a un puesto no registrado por falta de mejores opciones de empleo. Por lo tanto, concluyen, un elevado desempleo induce a los individuos a aceptar peores condiciones laborales, posiciones informales de bajos salarios. En este contexto, la informalidad resulta contracíclica.

\subsection{Incentivos a la formalización}

Argentina implementó varias reducciones en las contribuciones de los empleadores. En 2001, el recorte se aplicó a cada nuevo trabajador contratado por empresas que estaban expandiendo su personal. En 2004, la reducción se limitó a las empresas con hasta ochenta empleados, y más tarde, en 2008, se extendió a todos los empleadores, mientras que la tasa de impuestos se redujo aún más. Castillo et al. (2012) evalúan el impacto de la reforma de 2008 y concluyen que contribuyó a mantener la demanda laboral formal en el grupo de empresas tratadas: se crearon 96,000 nuevos empleos en estas empresas, en comparación con una pérdida de 5,000 empleos en el grupo de control.

Cruces et al. (2010), por el contrario, evalúan el impacto de la reducción en las contribuciones sociales observada en Argentina durante el período 1995-2001 en el empleo agregado y los salarios. No encuentran un impacto significativo en la primera variable, pero habría posibilitado aumentos en el salario de los trabajadores formales.

Chacaltana (2001) encuentra que las reformas del mercado de trabajo peruano de la década de 1990, que desregularon la contratación y el despido, no generaron un aumento en la formalización laboral. Al mismo tiempo, la importante reducción del costo de la mano de obra para las PYME, primero en 2003 y luego en 2008, tuvo efectos pequeños o nulos en el registro (Chacaltana 2008).

En Brasil, el programa Simples Nacional se implementó en 1996 con el objetivo de simplificar los procedimientos de registro y reducción de impuestos para las pequeñas y microempresas. A su vez, la Lei do Microempreendedor Individual (Ley de emprendedores individuales) aprobada en 2009 también simplificó el proceso de registro para microempresas con hasta un empleado, y redujo los costos de las contribuciones a la seguridad social. Fajnzylber et al. (2009), Delgado et al. (2007) y Monteiro y Assunção (2012) encuentran efectos positivos del 
Beccaria y Maurizio / Revista de Economía Laboral 15(2) (2018), 8-56

programa Simples en los niveles de registro. Berg (2010) y Krein y Dos Santos (2012) también concluyen que este programa ha sido positivo en el crecimiento de la formalidad.

Por el contrario, Henrique de Andrade et al. (2013) evalúan el programa SIMPLES en Brasil pero no identifican impacto alguno generado por la mayor información y la exención en los aranceles de registro de firmas.

Al igual que en Brasil, en 2006 Argentina lanzó el programa Mi Simplificación, un programa de simplificación del registro que establece un procedimiento único para el registro de trabajadores y empleadores y para el posterior control del cumplimiento de las normas laborales. Ronconi y Colina (2011) encuentran efectos positivos, aunque pequeños en los niveles de registro.

Castillo et al. (2007) indican, sin embargo, que no hay evidencia que demuestre que la simplificación de los procedimientos haya tenido un impacto positivo en términos de reducción de la informalidad en América Latina. Esto se debe, al menos en parte, al hecho de que los costos de registro de la actividad productiva representan una proporción menor de los costos totales. También argumentan que la reducida tasa de registración reside en la baja productividad de las empresas, cuya solución no parece ser solo, o incluso esencialmente, la simplificación de los procedimientos de registro, sino estrategias más completas y complejas que incluyen un mejor acceso al crédito, los mercados y la tecnología, entre otros determinantes.

Por lo tanto, esos resultados parecen sugerir que los esquemas para simplificar el registro son necesarios para apoyar la formalización de las pequeñas empresas, pero claramente no son suficientes para alcanzar ese objetivo y que, por lo tanto, se necesita una amplia gama de instrumentos que promuevan el desarrollo productivo de dichos establecimientos.

Asimismo, las políticas de reducción de aportes patronales pueden o no tener un impacto significativo en el registro, tanto en lo que hace a la "legalización" de trabajadores contratados previamente de manera informal, sin modificar el número de empleados, como a la generación de nuevos empleos formales. En lo que hace a este mecanismo las explicaciones por las cuales el incentivo pueden resultar insuficiente son diversas: bajos rendimientos que hacen imposible asumir otros costos asociados con la formalidad (salario mínimo, costos de despido, etc.), incertidumbre sobre el futuro o el hecho de que la relación laboral se está ocultando como parte de un esquema de evasión de impuestos más amplio. 


\subsection{El rol de la inspección laboral}

Finalmente, en varios países de América Latina, los costos de la no formalización que enfrentan los empleadores aumentaron como resultado de las medidas implementadas para fortalecer y mejorar la inspección del trabajo. El Plan Nacional de Regularización Laboral, establecido en Argentina en 2004, reforzó los controles para detectar el empleo asalariado no registrado en el sistema de seguridad social. Con este plan, se le asignó al Ministerio de Trabajo el papel de coordinador nacional para este tipo de actividad. Además, las tecnologías empleadas mejoraron y el número de inspectores aumentó de cuarenta en 2003 a 470 en 2011. Del total de inspecciones realizadas durante ese período, el $28 \%$ de los trabajadores no se registraron debidamente y alrededor del 37\% de estos últimos se formalizaron después de la inspección. Ronconi (2010) encuentra un impacto positivo de las inspecciones en la formalización en Argentina. De hecho, el número de trabajadores formalizados aumentó debido a las inspecciones durante ese período de 17,000 en 2005 a 47,000 en 2011, con un incremento de 10 puntos porcentuales en la tasa de formalización entre 2005 y 2012 (según datos del Ministerio de Trabajo).

En Brasil, el fortalecimiento de la inspección del trabajo no se asoció con un aumento en el número de inspectores sino con una mayor efectividad de la inspección debido a la implementación de cambios organizacionales y reformas en la estructura de incentivos. Según Pires (2009), a mediados de la década de 1990 se introdujo un sistema de bonos para los inspectores que vinculaba parte de sus salarios al desempeño individual y grupal. Luego, se crearon equipos especiales de inspección para tratar situaciones más complejas en ciertos sectores. Berg (2010) señala que estos dos nuevos enfoques tuvieron efectos positivos significativos en la formalización laboral en Brasil.

Asimismo, Almeida y Carneiro (2009) encuentran que las regiones con controles más estrictos en Brasil presentaron tasas de informalidad más bajas. No encuentran efectos negativos de las inspecciones en el empleo total, lo que sugiere que el empleo formal reemplazó al empleo informal. Los resultados de la evaluación de impacto de Henrique de Andrade et al. (2013) también muestran que la inspección fue el único instrumento eficaz en Belo Horizonte (Brasil) para inducir la formalización ya que ni los mayores niveles de información ni los incentivos monetarios tuvieron un impacto significativo.

En Ecuador, también se llevó a cabo un proceso para fortalecer la institución de la inspección del trabajo. En 2011, se lanzó el programa 
Trabajo Digno que permitió al Ministerio de Relaciones Laborales aumentar el número de inspectores (de 65 en 2006 a 245 en 2011) y modificar la organización de su trabajo. Un estudio del World Bank (2012), basado en una encuesta empresarial de 2011, destaca el papel de esta herramienta en la lucha contra la informalidad, afirmando que las inspecciones fueron cada vez más frecuentes, con aproximadamente el $60 \%$ de las firmas en la muestra que declararon ser inspeccionadas al menos una vez durante el año anterior. El estudio también encontró una correlación positiva y estadísticamente significativa entre el hecho de haber sido inspeccionado y el cumplimiento de las normas legales y laborales. Esa correlación, sin embargo, no es perfecta; por ejemplo, alrededor del $12 \%$ de las empresas inspeccionadas continuaron operando sin tener un número de identificación fiscal. Al mismo tiempo, mientras que el porcentaje de firmas que cumplen con la legislación laboral fue de alrededor de 30 p.p. más alto entre los que habían sido inspeccionados que entre las que no lo habían sido, la mitad de las primeras no había registrado a sus trabajadores en el Instituto Ecuatoriano de Seguridad Social (IESS).

En 2011, se celebró un referéndum nacional y una consulta pública sobre diversos aspectos, incluida la cuestión de la penalización por el incumplimiento de las obligaciones de seguridad social por parte de los empleadores. La pregunta decía: “¿Está usted de acuerdo con que la Asamblea Nacional, sin dilaciones dentro del plazo establecido en la Ley Orgánica de la Función Legislativa, a partir de la publicación de los resultados del plebiscito, tipifique como infracción penal la no afiliación al Instituto Ecuatoriano de Seguridad Social de los trabajadores en relación de dependencia?" La propuesta fue aprobada. Si bien el impacto de esa reforma no se ha evaluado directamente, en 2011 la afiliación a la seguridad social creció significativamente, en consonancia con el aumento en la formalidad laboral mencionado anteriormente. Específicamente, de acuerdo con la información proporcionada por el IESS, la afiliación a la seguridad social aumentó del 33\% en 2010 al 38\% en 2011. El número de empleadores registrados aumentó en casi un 50\% en esos dos años. Según World Bank (2012), si bien no es posible afirmar que este aumento se deba únicamente al cambio en la legislación, que todavía no había entrado en vigor ese año, se considera que la señal enviada en términos de no tolerancia a la informalidad (que reforzó la agenda iniciada con el cambio de la Constitución en 2008) ayudó a estimular el registro.

En resumen, los pocos estudios que evalúan el impacto de las inspecciones parecen confirmar que tienen un efecto positivo en la 
formalidad del mercado laboral. Algunos también han encontrado efectos negativos en el empleo total o en los salarios. Esto reforzaría la idea de que ciertas empresas, especialmente las más pequeñas, como ya se dijo, operan informalmente porque no pueden pagar los costos asociados con la regularización de la empresa y sus trabajadores. La combinación y coordinación de la inspección con políticas de diversas naturalezas para promover el crecimiento productivo, la rentabilidad y la competitividad son indispensables en esos casos.

\section{Síntesis y conclusiones}

El empleo asalariado informal, aquel que no cumple con las normas laborales y/o de seguridad social, constituye una proporción significativa de la ocupación total en los países de América Latina. Sin embargo, el mismo ha reducido su tamaño relativo desde principios de los 2000 y hasta, aproximadamente, medidos de la década siguiente.

Este documento analizó algunas de las características de esa evolución a partir de la evidencia de cinco países para lo cual se recurrió a información no sólo de carácter estático, que permite examinar los cambios netos experimentados por la cantidad de distintos tipos de puestos, sino también a aquella de tipo longitudinal que da cuenta de las transiciones que se producen entre diferentes tipos de empleos. Los países identifican a los asalariados formales a través del uso de distintos tipos de preguntas (existencia de contratos, inscripción en la seguridad social, percepción de seguro social); si bien ello podría plantear alguna limitación al análisis comparativo, se considera que esta es de escasa relevancia en tanto esos diferentes formas adoptadas en las encuestas identifican adecuadamente al aspecto central de la formalidad legal que es el cumplimiento de las normas laborales.

Precisamente, este último tipo de datos permitió identificar uno de los rasgos más llamativos de ese proceso de formalización del empleo en la región como ha sido la elevada contribución de la regularización de asalariados en el mismo puesto de trabajo en el que se venían desempeñando sin estar registrados: lo que se ha denominado la "formalización in situ". Entre un 30 y 40\% de las nuevas ocupaciones formales que se crearon en el período se verificó a través de este canal.

La formalización benefició en mayor medida a aquellos que presentaban un "mejor" vector de características, esto es, los relativamente más calificados o más educados. En el caso de la regularización in situ, el proceso también fue más intenso entre quienes trabajaban a tiempo completo o contaban con mayor antigüedad en el 
puesto. Ello ha tendido a amplificar la brecha de formalidad inicial observada entre los individuos definidos de acuerdo con estas categorías.

Ese aumento de la incidencia de empleos registrados en América Latina estuvo estrechamente ligado al intenso y sostenido crecimiento económico experimentado por la región (incluido los países analizados) durante el período que transcurrió, aproximadamente, a lo largo de los primeros quince años del nuevo siglo. Una dinámica productiva de estas características se asocia a, al menos, a dos desarrollos que favorecen la expansión del empleo formal. Por un lado, eleva la probabilidad de realizar contrataciones de largo plazo; por el otro, mejora la productividad (o rentabilidad) de las empresas en general, incluida las informales, lo cual permite que, especialmente estas últimas -entre las cuales la no registración laboral es muy elevada- regularicen a (parte de) sus trabajadores y/o creen nuevos puestos registrados.

La influencia del crecimiento agregado está mediada, sin embargo, por diversos factores que pueden intensificar o menguar sus efectos sobre la creación de puestos formales. En particular, durante el período bajo análisis se desplegaron en varios de los países analizados diversas políticas que pudieron, al menos potencialmente, haber contribuido a elevar la incidencia del empleo registrado. Estas fueron, por un lado, aquellas que redujeron el costo laboral. Por otro lado, las mejoras en la inspección del trabajo.

Las políticas mencionadas parecen tener efectos en el marco de contextos económico favorables. En los últimos años del período analizado, cuando las economías de la región desaceleraron su crecimiento, y aún exhibieron caídas de su PIB en algunos años, las intervenciones públicas se mantuvieron, pero no fueron suficientes para sostener el aumento de la formalidad.

Por otro lado, si bien el período bajo análisis muestra las posibilidades de ir avanzando en la extensión de la cobertura de los derechos laborales en América Latina, también da cuenta de las limitaciones que el mismo enfrenta. Ello parece estar ligado al hecho que la elevada presencia de empleos informales en los mercados de trabajos latinoamericanos resulta en buena medida del importante peso del sector informal en sus estructuras productivas, y que se deriva de la incapacidad que, en el largo plazo, han exhibido esas economías para lograr un crecimiento sostenido y que absorba los aumentos de la oferta laboral. En ese sentido, avances significativos en la formalización parecen requerir procesos de crecimiento intensos y estables, pero también orientados a reducir la importancia de los segmentos de mayor informalidad de su estructura productiva. Los resultados del análisis 
realizado muestran, por ejemplo, que aún en un período favorable como el analizado, la proporción de trabajadores regularizados in situ fue menor entre las firmas pequeñas que entre las medianas y grandes. Avanzar en aquel objetivo parece requerir, entonces, no sólo medidas a nivel micro como las examinadas -las que de cualquier manera deberían continuar formando parte del paquete de intervenciones- sino también políticas a nivel macro y meso.

\section{Referencias bibliográficas}

Almeida, M. (2008), Além da informalidade: entendendo como os fiscais e agentes de desenvolvimento promovem a formalização e crescimento de pequenas e médias empresas, Texto para discussão No 1353, IPEA, Rio de Janeiro.

Almeida, R. y Carneiro, P. (2009), 'Enforcement of Labor Regulation and Firm Performance', Journal of Comparative Economics, 37(1), 28-46.

Amarante, V. y R. Arim (ed.) (2015), Desigualdad e Informalidad. Un análisis de cinco experiencias latinoamericanas, CEPAL-Ministerio de Asuntos Exteriores de Noruega, Santiago de Chile.

Arulampalam W; Booth, A. y Bryan, M. (2004), "Training in Europe", Journal of the European Economic Association, 2(2-3), 346-360.

Ashenfelter, O. y Smith, R. (1979), 'Compliance with the Minimum Wage Law', Journal of Political Economy, 87(2), 333-350.

Bassanini, A., Booth, A., Brunello, G., De Paola, M. y Leven, E. (2005), Workplace Training in Europe, IZA Discussion Paper No. 1640, Bonn.

Beccaria, L. (2015), "Perspectivas de políticas de formalización de la economía informal", en Bertranou, F. y Casanovas, L. (Coord.) Caminos hacia la formalización laboral en Argentina, OIT, Buenos Aires, 185-206.

Beccaria, L., Maurizio, R., Trombetta, M., y Vázquez, G.(2016), "Una evaluación del efecto scarring en Argentina”, Revista Desarrollo y Sociedad, N. ${ }^{\circ} 77,263-304$. 
Beccaria, L., Maurizio, R. y Vázquez, G. (2015a), "Recent decline in wage inequality and formalization of the labor market in Argentina", International Review of Applied Economics, 29 (5), 677-700.

Beccaria, L., Maurizio, R. y Vázquez, G. (2015b), "Desigualdad e informalidad en América Latina: el caso de la Argentina", en Amarante, V. y Arim, R. (ed.), Desigualdad e Informalidad. Un análisis de cinco experiencias latinoamericanas, CEPAL-Ministerio de Asuntos Exteriores de Noruega, Santiago de Chile, 89-128.

Beccaria, L. y Maurizio, R. (2018), "Labor turnover in Latin America. How intensive is it and how differently does it behave across countries?", International Labour Review, en prensa.

Berg, J. (2010), 'Laws or luck? Understanding rising formality in Brazil in the 2000s'. ILO Working Paper $\mathrm{N}^{\circ}$. 5, International Labour Office, Brasilia.

Bertranou, F., Casanova, L. y M. Saravia (2013), How, Why and in What Sectors Employment Informality Decreased in Argentina from 2003 to 2012, MPRA Paper No 47467, University Library of Munich, Munich.

Blau, F. y Kahn, L. (1981), "Causes and consequences of layoffs", Economic Inquiry 19 (2), 270-296.

Blau, F., Ferber, M. y. Winkler, A. (2002), The economics of women, men, and work, Prentice Hall, Upper Saddle River.

Bosch, M. y Esteban-Pretel, J. (2009), Cyclical informality and unemployment. CIRJE Discussion Paper No 613,Tokyo: CIRJE.

Booth, A., Francesconi, M. y Frank, J. (2002), “Temporary Jobs: Stepping Stones or Dead Ends?", The Economic Journal, 112(480), F189-F213.

Cantó, O, Del Río, C. y Gradín, C. (2007), "What helps households with children in leaving poverty?: Evidence from Spain”, en Bishop, J. y Amiel, Y. (eds.) Inequality and Poverty (Research on Economic Inequality, Volume 14) Emerald Group Publishing Limited, 1 - 29.

Carpio, S., Giuliodori, D., Rucci, G. y Stucchi R (2011), The effects of temporary contracts on human capital accumulation in Chile. Working 
Paper Series Nº. IDB-WP-253, IDB, Washington.

Castillo, G., Gutiérrez, I. y Stumpo, G. (comp.) (2007), Simplificación de trámites para la creación de empresas: La experiencia de Fundes. Cepal - Fundes, Santiago de Chile.

Castillo, V., Rojo Brizuela, R. y Schleser, D. (2012), 'El impacto de las políticas laborales contracíclicas sobre el empleo asalariado registrado', en MTEySS-ILO (eds.) Macroeconomía, empleo e ingresos: debates y politicas en Argentina frente a la crisis internacional 2008-2009, . Ministerio de Trabajo y Seguridad Social (Argentina)-OIT, Buenos Aires: 216-59.

Cazes, S. y Verick, S. (ed.) (2013), Perspectives on labour economics for development, International Labour Office, Geneva.

CEPAL-OIT (2015), Coyuntura Laboral en América Latina y el Caribe, CEPAL-OIT, Santiago de Chile.

Cerruti, M. (2000), "Intermittent employment among married women: a comparative study of Buenos Aires and México City", Journal of Comparative Family Studies, 31(1), 19-43.

Chacaltana, J. (2001), "Reforma en la contratación y el despido en el Perú de los noventa”, Revista Economía, 24(48), 133-151.

Chacaltana, J. (2008), na evaluación del régimen laboral especial para la microempresa en Perú, al cuarto año de vigencia OIT, Lima.

Corseuil, C. y Foguel, M. (2012), 'Economic Expansion and Increase in Labour Market Formality: A Poaching Approach', Revista Brasileira de Economia 66(2): 207-224.

Cruces, G., Galiani, S. y Kidyba, S. (2010), "Payroll Taxes, Wages and Employment: Identification through Policy Changes", Working Paper $\mathrm{N}^{\mathrm{o}}$. 93, CEDLAS, La Plata.

Cruces, G., Ham, A. y Viollaz, M. (2012), Scarring effects of youth unemployment and informality Evidence from Brazil, mimeo.

Cunningham, W. y Salvagno, J. (2011), Youth Employment Transitions 
in Latin America, Policy Research Working Paper N. 5521, World Bank, Washington.

Damill, M., y Frenkel, R. (2012), Macroeconomic Policies, Growth, Employment, and Inequality in Latin America, Working Paper $\mathrm{N}^{\mathrm{o}}$.. 2012/23, UNU-WIDER, Helsinki.

Delgado, G., Querino, A., Campos, A., Vaz, F., Rangel, L. y M. Stivali (2007), 'Avaliação do Simples: Implicações à Formalização Previdenciária'. Texto para discussão No ${ }^{\circ}$ 1277, IPEA, Brasilia.

Fajnzylber, P.; Maloney, W. y G. Rojas (2009), Does formality improve micro-firm performance? Quasi-experimental evidence from the Brazilian SIMPLES program. Discussion Paper N. 4531, IZA, Bonn

Farber, H. (1999), "Mobility and stability: the dynamics of job change in labor markets" en Ashenfelter, O. y Card, D. Handbook of labor economics (Volume 3, Part B), Elsevier, Amsterdam, 2439-2483.

FORLAC (2014a), "Evolución del empleo informal en Ecuador: 2009 2012”, OIT (Oficina Regional para América Latina y el Caribe), Lima.

FORLAC (2014b), "Políticas para la formalización de las micro y pequeñas empresas”, , OIT (Oficina Regional para América Latina y el Caribe), Lima.

FORLAC (2016), "Políticas de formalización del trabajo doméstico remunerado en América Latina y el Caribe”, OIT (Oficina Regional para América Latina y el Caribe), Lima.

Galli, R. y Kucera, D. (2003), Informal employment in Latin America: Movements over business cycles and the effects of worker rights Informal employment in Latin America, Discussion paper DP/145/2003, International Institute for Labour Studies ( ILO), Geneva.

Henrique de Andrade, G., Bruhn, M. y D. McKenzie (2013), A Helping Hand or the Long Arm of the Law? Experimental Evidence on What Governments Can Do to Formalize Firms. Policy Research Working Paper $\mathrm{N}^{\mathrm{o}}$. 6435. World Bank, Washington.

Hussmanns, R. (2004), Measuring the informal economy: From 
employment in the informal sector to informal employment, Policy Integration Department Working Paper Nº. 53.: ILO, Geneva.

ILO (2002), Resolution concerning decent work and the informal economy. Governing Body, 285th Session, Seventh item on the agenda, Geneva.

Jenkins, S. y Schluter, C. (2003), "Why are Child Poverty Rates Higher in Britain than in Germany? A Longitudinal Perspective", Journal of Human Resources, XXXVIII(2), 441- 465.

Krein, J. y A. Dos Santos (2012), 'A formalização do trabalho: crescimento econômico e efeitos da política laboral no Brasil', Nueva Sociedad N . 239, 90-101.

Kucera, D. y Roncolato, L. (2008), 'Informal employment: two contested policy issues', International Labour Review 147 (4), 321-48.

Madalozzo, R. and A, Bortoluzzo (2011), The impact of tax exemptions on labor registration: The case of Brasilian domestic workers, Working Paper $N^{0}$. 232, Insper Instituto de Ensino e Pesquisa, Sao Pablo.

Maurizio, R. (2015), "Transitions to formality and declining inequality: Argentina and Brazil in the 2000s", Journal of Development and Change, vol. 46(5), 1047-1079.

Maurizio, R. y Vázquez, G. (2015), "Desigualdad e informalidad en América Latina: el caso del Ecuador", en Amarante, V. y Arim, R. (ed.) Desigualdad e Informalidad. Un análisis de cinco experiencias latinoamericanas, CEPAL-Ministerio de Asuntos Exteriores de Noruega, Santiago de Chile, 211-244.

Mincer, J. y Jovanovic, B. (1981), "Labor mobility and wages", en S. Rosen (ed.) Studies in Labor Markets, University of Chicago Press, Chicago, 21-63.

Monteiro, J. y Assunção, J. (2012), 'Coming out of the shadows? Estimating the impact of bureaucracy simplification and tax cut on formality in Brazilian microenterprises', Journal of Development Economics 99(1), 105-115.

Pires, R. (2009), 'Governing regulatory discretion: innovation, 
performance and accountability in two models of inspection work'. Documento presentado en la Conferencia "Regulating for Decent Work", OIT, Geneva.

Ronconi, L. (2010), 'Enforcement and compliance with labor regulations', Industrial and Labor Relations Review 63(4), 719:36.

Ronconi, L. y Colina, J. (2011), 'Simplificación del registro laboral en Argentina. Logros obtenidos y problemas pendientes', Working Paper $\mathrm{N}^{\circ}$. 277. BID, Washington.

Stiglitz, J. (1974), "Alternative theories of wage determination and unemployment in LDCs: The labor turnover model", Quarterly Journal of Economics, 88(2), 194-227.

World Bank (2012), "Ecuador. Las caras de la informalidad", Informe No. 67808-EC, Banco Mundial, Washington.

Zijl, M., van den Berg, G. y Heyma, A. (2009) "Stepping stones for the unemployed: the effect of temporary jobs on the duration until (regular) work", Journal of Population Economics 24(1), 107-139. 